\title{
Fuzzy Logic Controller Implementation of Power Quality Improvement Using UPQC
}

\author{
S. Balaslubramaniyan1, T. S. Sivakumaran² \\ ${ }^{1}$ Department of EEE, Mailam Engineering College, Mailam, India \\ ${ }^{2}$ Department of EEE, Arunai College of Engineering, Tiruvannamalai, India \\ Email: balasipi@yahoo.co.in, sivakumarants@arunai.edu.in
}

How to cite this paper: Balaslubramaniyan, S. and Sivakumaran, T.S. (2017) Fuzzy Logic Controller Implementation of Power Quality Improvement Using UPQC. Circuits and Systems, 8, 202-226. https://doi.org/10.4236/cs.2017.88014

Received: May 6, 2016

Accepted: May 13, 2016

Published: August 28, 2017

Copyright () 2017 by authors and Scientific Research Publishing Inc. This work is licensed under the Creative Commons Attribution International License (CC BY 4.0).

http://creativecommons.org/licenses/by/4.0/

Open Access

\begin{abstract}
This paper presents a gross examination about Unified Power Quality Conditioner (UPQC) to invigorate the power issues at the distribution level of the electrical system. Nowadays power electronics research has added the importance of power quality studies, for concrete illustration, Custom Power Devices (CPD) and Flexible AC Transmission position (FACTS) devices. The approach offered in this paper utilizes the series and shunt compensator of Unified Power Quality Conditioner (UPQC) to inject a compensation voltage inphase with the source current over voltage fluctuations. The execution of two structures of UPQC, left-shunt (L-UPQC) and right-shunt (R-UPQC) are investigated under diverse operating conditions based on the fuzzy logic controller to raise the value of power quality of a single feeder distribution system by MATLAB/Simulink programming. Various power quality issues have been analyzed in this study. Finally, the right shunt UPQC is outperformed in this proposed power system.
\end{abstract}

\section{Keywords}

Left Shunt UPQC, Right Shunt UPQC, Fuzzy Logic Controller, Power Quality

\section{Introduction}

Power quality issues are getting increasingly massive in nowadays in the break of the expanding number of power electronic devices that hold on as nonlinear loads. A generous assorted status of answers for power quality issues is noticeable for distribution network operator and the end user [1]. The power handling at the source, load and for reactive and harmonic compensation by power electronic devices are getting preferably prevalent due to the vast advantages offered by them. The shunt active power filter (APF) is consistently associated with the 
loads to compensate for all told current related issues, for example, the reactive power compensation, power factor improvement, current harmonic compensation, and load unbalance compensation, whereas the series active power filter is installed in a series mutually a line through the series transformer. It acts as controlled voltage source and can reimburse all voltages associated glitches, for example voltage sag, voltage harmonics, voltage swell, flicker, etc. [2]. UPQC is a Custom Power Device and consists of arm in arm series active power filter that reimburses voltage unbalances, voltage harmonics, voltage sag/swell, voltage flicker and shunt active power filter that compensates current harmonics, current unbalance and reactive current [3].

UPQC is well known as the universal active power line conditioner, universal power quality conditioning system, and universal active filter [4] [5]. UPQC system can be cut apart into two sections: The control unit and the power circuit. The control unit includes disruption detection, reference signal generation, the gate signal generation and voltage/current measurements. Power circuit contains of two voltage source converters, standby and system protection system, harmonic filters and injection transformers. Power electronic based appliance, such as Flexible AC Transmission Systems (FACTS), High-Voltage DC (HVDC), and Custom Power technologies comprise some of the closely promising technical advancements to address the new operational challenges being presented today. These advancements are based on the high-performance capacity of the power electronic appliance to accept rapidly to system events, grow power transfer limits, and invigorate the quality of power delivered.

With respect to the Custom Power necessities [6], utility distribution networks, sensitive industrial loads, and critical commercial operations can possibly experience the ill effects from various types of outages and service interruptions. These can cost significant financial losses per incident based on occurrence downtime, lost production, inactive workforces, and other measurable and nonmeasurable factors. The sorts of interruptions experienced are named power quality issues and are frequently brought on by voltage sags and swells, lightning strikes, and other distribution system related disturbances. In numerous cases, the utilization of Custom Power equipment, for example, Dynamic Voltage Restorers (DVR), Solid-State Transfer Switches (SSTS), or Distribution level Static Compensators (D-STATCOM), can be probably the most practical answers for moderate these sorts of power quality issues. There have been various uses of Custom Power technologies [7]-[13].

A standout amongst the most productive frameworks to take care of power quality issues is Unified Power Quality Conditioner (UPQC). It comprises of a Parallel and a Series-Active Filter together with a typical DC link [14]. Custom power devices have utilized as a part of the distribution system and for the improvement of current issues, parallel active filters, for example, DSTATCOM. The examination and investigation of the control plans for power quality improvement and control have been considered in [15]. A unified series-shunt 
compensator (USSC) went for inspecting its ability in enhancing power quality in a power distribution system. The USSC simulation model includes 12-pulse inverters, which are associated in arrangement and shunt to the system. A generalized sinusoidal pulse width modulation switching technique is created by Hannan [16]. This mix permits a simultaneous compensation for source side currents and delivered voltage to the load.

In this way, the operation of the UPQC secludes the utility from current quality issues of load and in the meantime isolates the load from the voltage quality problems of utility.

The point of this work to present the power quality issues and to discuss the solutions of some of these problems is using power electronic controllers. The paper examines the power quality problems with UPQC with the execution of the left shunt and right shunt connection of the proposed power system fuzzy logic controller approach.

\section{Unified Power Quality Conditioner (UPQC)}

The general diagram of an UPQC distribution network is shown in Figure 1. An UPQC combines an arrangement of a series and a shunt compensator together. The supply voltage is sinusoidal for unbalanced and nonlinear loads. The UPQC can likewise make the current drawn from the supply $\left(i_{s}\right)$ in phase with the terminal voltage $\left(v_{t}\right)$. Therefore, the voltage of any bus upstream from the PCC will not be pretentious due to a nonlinear and unbalanced load. Though, it will be problematic to rectify the unbalance and distortion created by the source voltage using this device. In this manner, the upstream bus voltages will remain unbalanced and distorted [17].

The single-line diagrams of these two systems are shown in Figure 2 and Figure 3. In these figures, the voltage at the PCC is concerned to as the terminal voltage $v_{t}$. The load voltage, load current, and source current are indicated by $v_{b}$ $i_{l}$ and $i_{s}$ respectively. $V_{d}$ indicates the voltage and current injected by the UPQC and if respectively. The source voltage is indicated by $V_{s}$, while $R$ and $L$ constitute the feeder impedance.

The UPQC shall perform the following two functions, one is to change the feeder (source) current is to adjust sinusoids through the shunt compensator and the second is to change the load voltage $\left(v_{I}\right)$ to balanced sinusoids through the series compensator besides control it to the desired value. Contingent upon the location of the shunt compensator on series compensator, the UPQC model

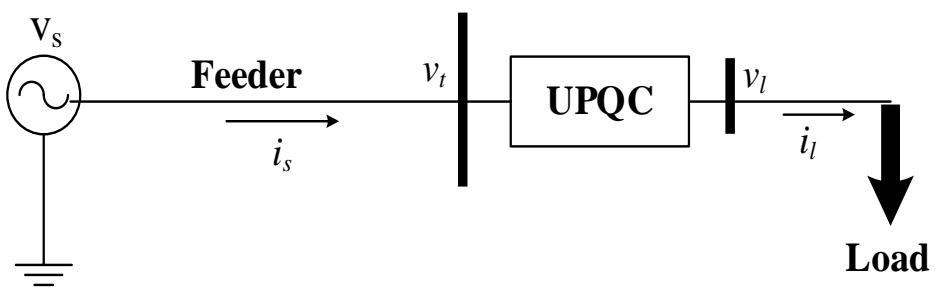

Figure 1. Example of a figure caption (figure caption). 


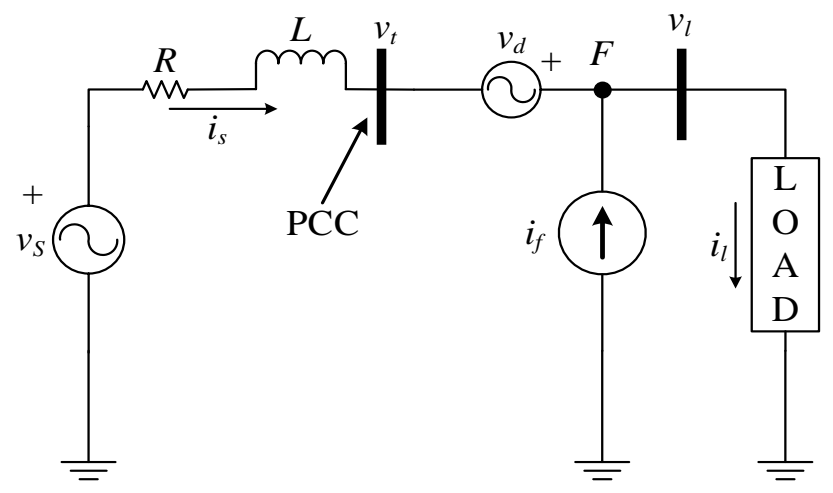

Figure 2. Right shunt UPQC compensation.

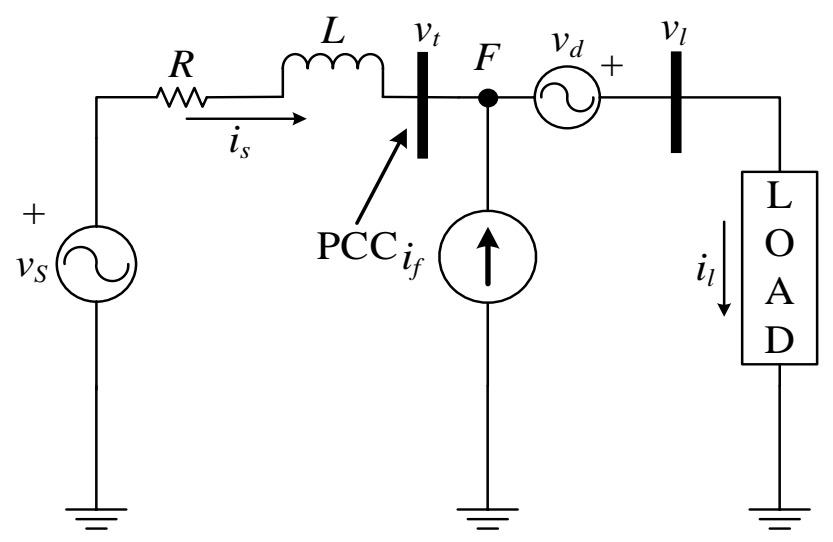

Figure 3. Left shunt UPQC compensation.

could be named as Right Shunt-UPQC or Left Shunt-UPQC. Both topologies of UPQC have similar features. The primary motivation behind UPQC and other similar custom power controllers is to detect voltage and current imperfections and after that give compensation or disconnection of custom power controllers from the distribution system.

\subsection{Left Shunt UPQC Configuration}

The left-shunt UPQC schematic is appeared in Figure 4. In this structure, a capacitor filter utilized for both series and the shunt inverters. The following issue won't emerge in the left shunt UPQC regardless of the possibility that we utilize capacitor filters with both shunt and series inverters. The equivalent circuit of the left shunt UPQC is appeared in Figure 5. For this situation, the shunt inverter tracks the terminal voltage $V_{t}$, and the series inverter keeps up the voltage over the load $V_{l}$ by following the voltage $V_{d}$. Hence, the two inverters track two quantities regardless of the possibility that they are independent. It is hence expected that the stability issue won't emerge for left-shunt UPQC structure.

Figure 5 demonstrates the single-phase equivalent circuit of the left shunt UPQC, the leakage inductance of the series transformer is signified by $L_{d \cdot}$ The switched voltage, over the shunt and series inverter output terminals are then signified by $V_{d c} u_{1}$ and $V_{d c} l_{2}$ separately. The state space equation of this circuit 


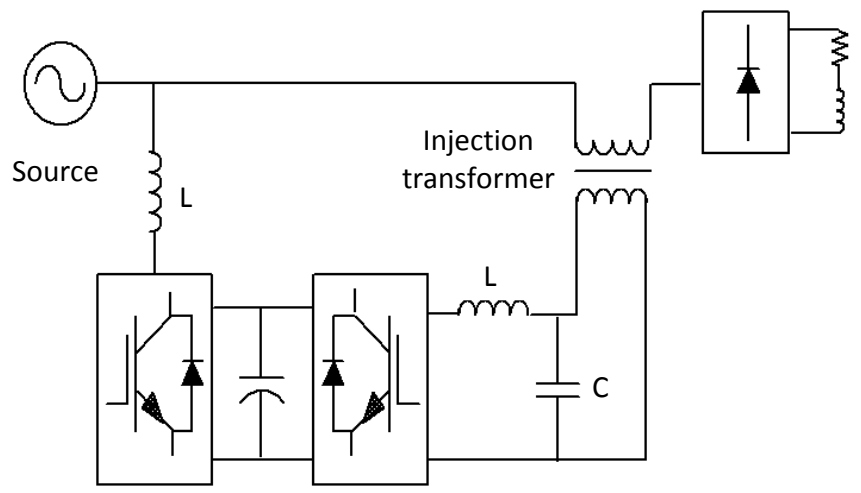

Figure 4. Left shunt UPQC configuration.

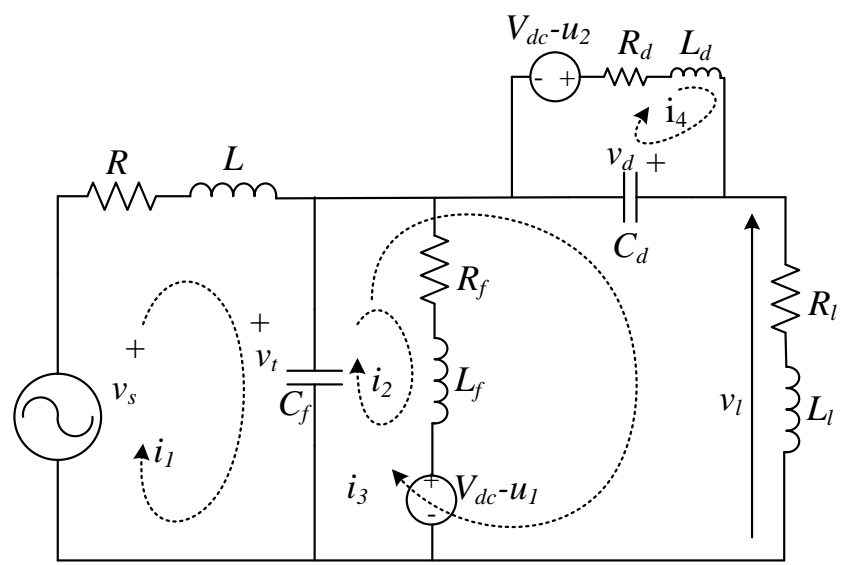

Figure 5. The equivalent circuit of Left shunt UPQC.

can likewise be composed with six state variables and two input variables. The state and input vectors are

$$
x^{\mathrm{T}}=\left[\begin{array}{llllll}
i_{1} & i_{2} & i_{3} & i_{4} & v_{t} & v_{d}
\end{array}\right], u^{\mathrm{T}}=\left[\begin{array}{ll}
u_{c 1} & u_{c 2}
\end{array}\right] .
$$

Moreover, the state space equation of the system is then given by,

$$
\dot{x}=A x+B_{1} u+B_{2} v_{s} .
$$

where

$$
A=\left[\begin{array}{cccccc}
-\frac{R}{L} & 0 & 0 & 0 & -\frac{1}{L} & 0 \\
0 & -\frac{R_{f}}{L_{f}} & 0 & 0 & -\frac{1}{L_{f}} & 0 \\
0 & 0 & -\frac{R_{l}}{L_{l}} & 0 & \frac{1}{L_{l}} & \frac{1}{L_{l}} \\
0 & 0 & 0 & -\frac{R_{d}}{L_{d}} & 0 & -\frac{1}{L_{d}} \\
\frac{1}{C_{f}} & -\frac{1}{C_{f}} & -\frac{1}{C_{f}} & 0 & 0 & 0 \\
0 & 0 & -\frac{1}{C_{d}} & \frac{1}{C_{d}} & 0 & 0
\end{array}\right]
$$




$$
\begin{aligned}
& B_{1}=\left[\begin{array}{cc}
0 & 0 \\
-\frac{V_{d c}}{L_{f}} & 0 \\
0 & 0 \\
0 & \frac{V_{d c}}{L_{d}} \\
0 & 0 \\
0 & 0
\end{array}\right] \\
& B_{2}=\left[\begin{array}{c}
\frac{1}{L} \\
0 \\
0 \\
0 \\
0 \\
0
\end{array}\right]
\end{aligned}
$$

\subsection{Right Shunt UPQC Configuration}

The schematic diagram of the right shunt structure appears in Figure 6. With the right shunt UPQC structure, the outputs of the VSIs realizing the shunt compensator are directly associated with three single-phase transformers. The phase sides of the secondary terminals are associated in shunt with the distribution feeder. Three filter capacitors, one for every phase, are likewise associated in shunt to give ways to the switching frequency harmonics created by the three VSIs. Three LC filters are attached to the three output terminals of the three VSIs realizing the series compensator. The secondary terminals of the three single-phase transformers are then associated with infuse voltages in series with the distribution feeder. The LC filters are utilized to bypass the switching frequency harmonics.

The single-phase equivalent circuit of the right shunt UPQC is appeared in Figure 7. In this figure $\mathrm{R}$ and $\mathrm{L}$ indicate the feeder parameters. $R_{I}$ and $L_{l}$ mean the load. The LC filter over the series inverter is spoken to by $L_{d}$ and $C_{d}$ while the resistance $R_{d}$ speaks to the inverter losses. The inductance $L_{T}$ signifies the leakage

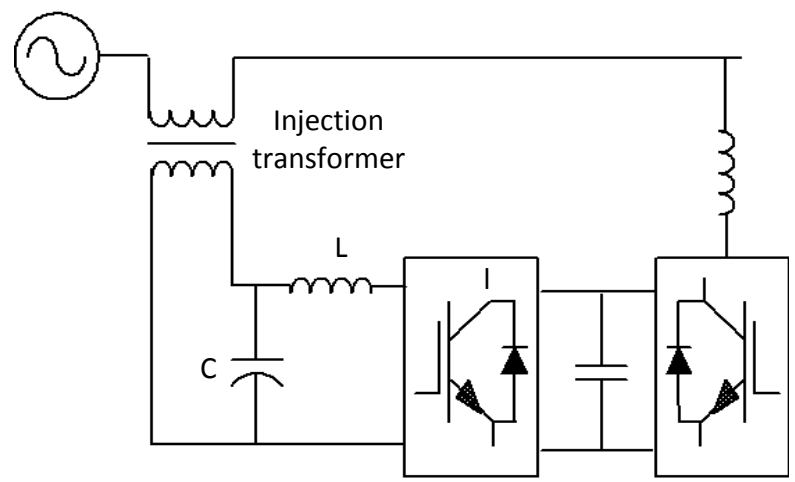

Figure 6. Right shunt UPQC configuration. 


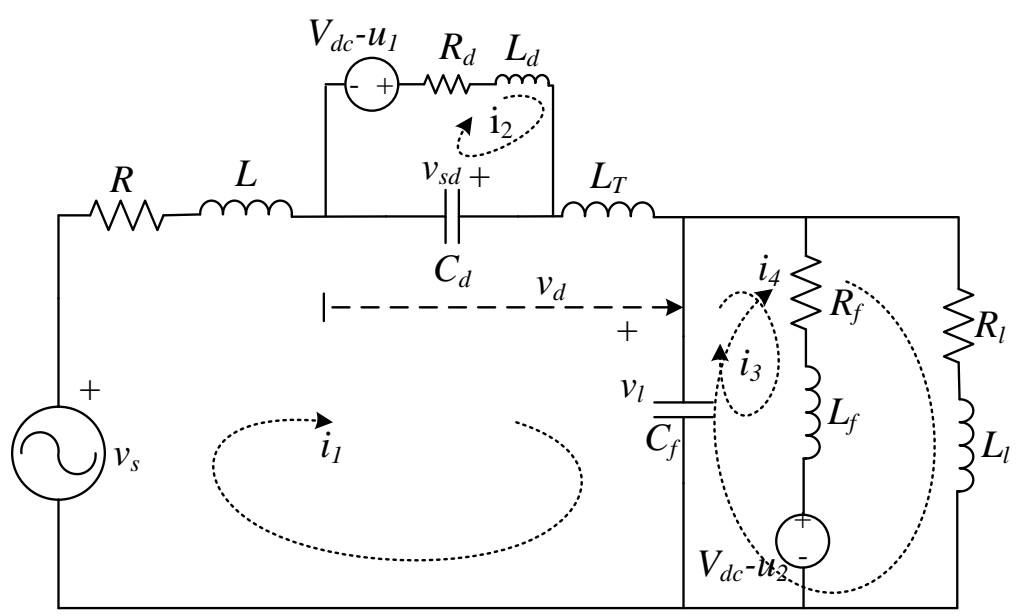

Figure 7. The equivalent circuits of right shunt UPQC.

inductance of the transformers associated with the series. The leakage inductance of the shunt transformer is indicated by $L_{f}$ while the resistance $R_{f}$ speaks to losses. The shunt filter capacitor is meant by $C_{f}$ the voltage at the load terminal is the voltage over this filter capacitor. The series injected voltage $V_{d}$ is appeared in Figure 7 while the voltage $V_{s d}$ is the voltage over the capacitor $C_{d}$. A typical capacitor supplies the series and shunt inverters. $V_{d c}$ signifies the voltage across this capacitor. The switched voltages over the series and shunt inverter yield terminals are then meant by $V_{d c} u_{1}$ and $V_{d c} u_{2}$ respectively.

From right-shunt UPQC structure, the tracking control, stability issue is staying away from through the choice of LC filter for the series inverter and capacitor filter for the shunt inverter. Consider the equivalent circuit; the inductance $L_{T}$ will be zero as the transformer leakage inductance will then be in series with the series inverter. However, a feedback control is required to track the voltages crosswise over both the capacitors and the absence of $L_{T}$ tracking voltage $V_{l}$ by the shunt compensator will make the tracking voltage $V_{d}$ over the series compensator repetitive and vice versa.

By driving the two inverters to track the voltages over their respective capacitors, the stability issue will emerge as one controller will meddle with the tracking execution of the other. Hence, to maintain a strategic distance from the tracking issue the LC filter structure for the series inverter is more appropriate for the right shunt UPQC. Likewise, the LC filter limits the switching frequency harmonics in the primary of the transformer associated with it.

To infer a state-space model of the system, that the circuit of contains six state variables - four loop currents and two capacitor voltages. It can be,

$$
x^{\mathrm{T}}=\left[\begin{array}{llllll}
i_{1} & i_{2} & i_{3} & i_{4} & v_{\text {sd }} & v_{l}
\end{array}\right] .
$$

The circuit of Figure 7 additionally contains three functions the voltage source $\mathrm{v}$ and switching variables $u_{1}$ and $u_{2}$. Give us a chance to supplant $u_{1}$ and $u_{2}$ by the continuous time variables $u c_{1}$ and $u c_{2}$ individually and characterize the accompanying control vector. 


$$
u^{\mathrm{T}}=\left[\begin{array}{ll}
u_{c 1} & u_{c 2}
\end{array}\right] .
$$

The state space equation of the framework is then given by

$$
\dot{x}=A x+B_{1} u+B_{2} v_{s} .
$$

where the $A, B_{1}$ and $B_{2}$ are given by

$$
\begin{aligned}
& A=\left[\begin{array}{cccccc}
-\frac{R}{L+L_{r}} & 0 & 0 & 0 & \frac{1}{L+L_{r}} & -\frac{1}{L+L_{r}} \\
0 & -\frac{R_{d}}{L_{d}} & 0 & 0 & -\frac{1}{L_{d}} & 0 \\
0 & 0 & -\frac{R_{f}}{L_{f}} & 0 & 0 & \frac{1}{L_{f}} \\
0 & 0 & 0 & -\frac{R_{l}}{L_{l}} & 0 & \frac{1}{L_{l}} \\
-\frac{1}{C_{d}} & \frac{1}{C_{d}} & 0 & 0 & 0 & 0 \\
\frac{1}{C_{f}} & 0 & -\frac{1}{C_{f}} & -\frac{1}{C_{f}} & 0 & 0
\end{array}\right] . \\
& B_{t}=\left[\begin{array}{cc}
0 & 0 \\
\frac{V_{d c}}{L_{d}} & 0 \\
0 & -\frac{V_{d c}}{L_{f}} \\
0 & 0 \\
0 & 0 \\
0 & 0
\end{array}\right] . \\
& B_{2}=\left[\begin{array}{c}
\frac{1}{L+L_{T}} \\
0 \\
0 \\
0 \\
0 \\
0
\end{array}\right] .
\end{aligned}
$$




\section{Fuzzy Logic Controller}

The fuzzy control gives a formal technique to speaking to, controlling, and executing a human's heuristic information about how to control a framework. Fuzzy memberships NL, NM, NS, ZE, PS, PM, PL is characterized as negative large, negative medium, negative small, zero, positive small, positive medium and positive significant. Figure 8 demonstrates the fundamental structure of a fuzzy logic controller.

The "fuzzy inference system" is a popular computing framework based on the ideas of fuzzy set theory, fuzzy if-then rules, and fuzzy reasoning [18]. It has found successful applications in a wide variety of fields, such as automatic control, data classification, decision analysis, expert systems, time series prediction, robotics, and pattern recognition [19]. Because of its multidisciplinary nature, the fuzzy inference system is known by various different names, such as "fuzzy expert system" [20], "fuzzy model" [21], "fuzzy associative memory" [22], and essentially "fuzzy system". Proposed fuzzy rule base surface perspective of UPQC system is appeared in Figure 9. Figure 10 demonstrates the internal architecture of the proposed fuzzy logic controller of UPQC system.

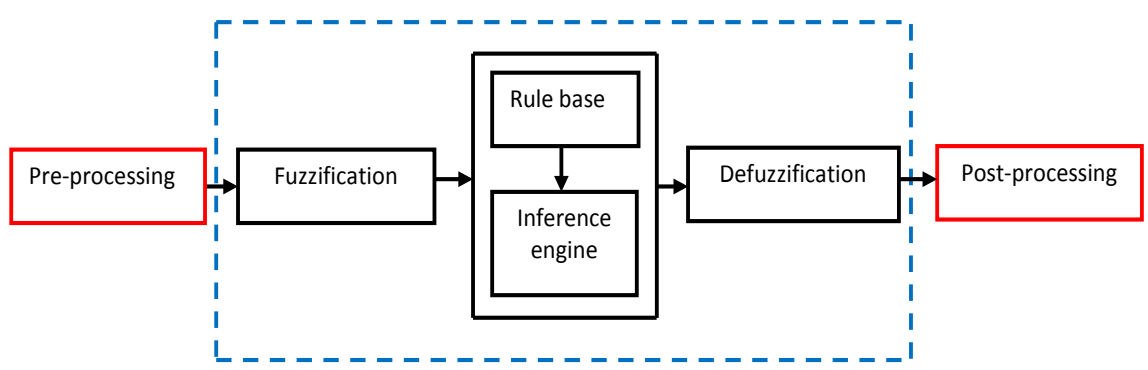

Figure 8. The fuzzy logic controller-basic structure representation.

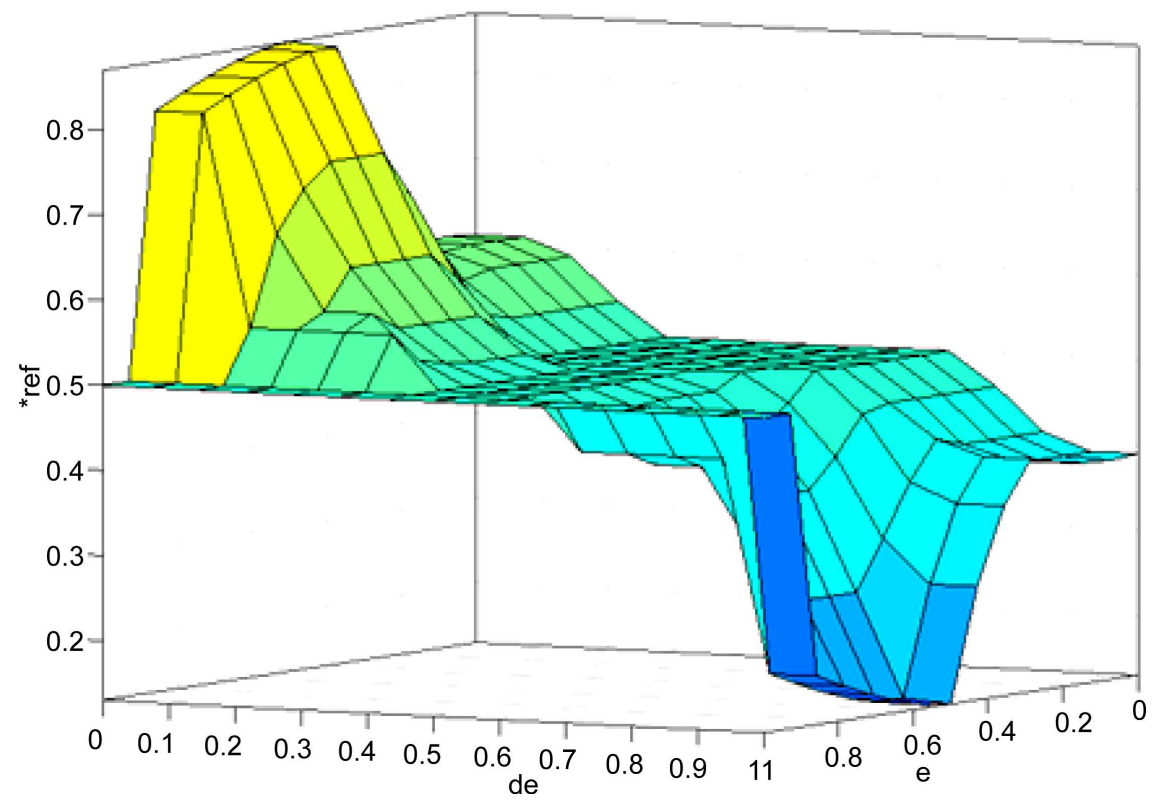

Figure 9. Prospective of rule base surface for UPQC system with fuzzy controller. 


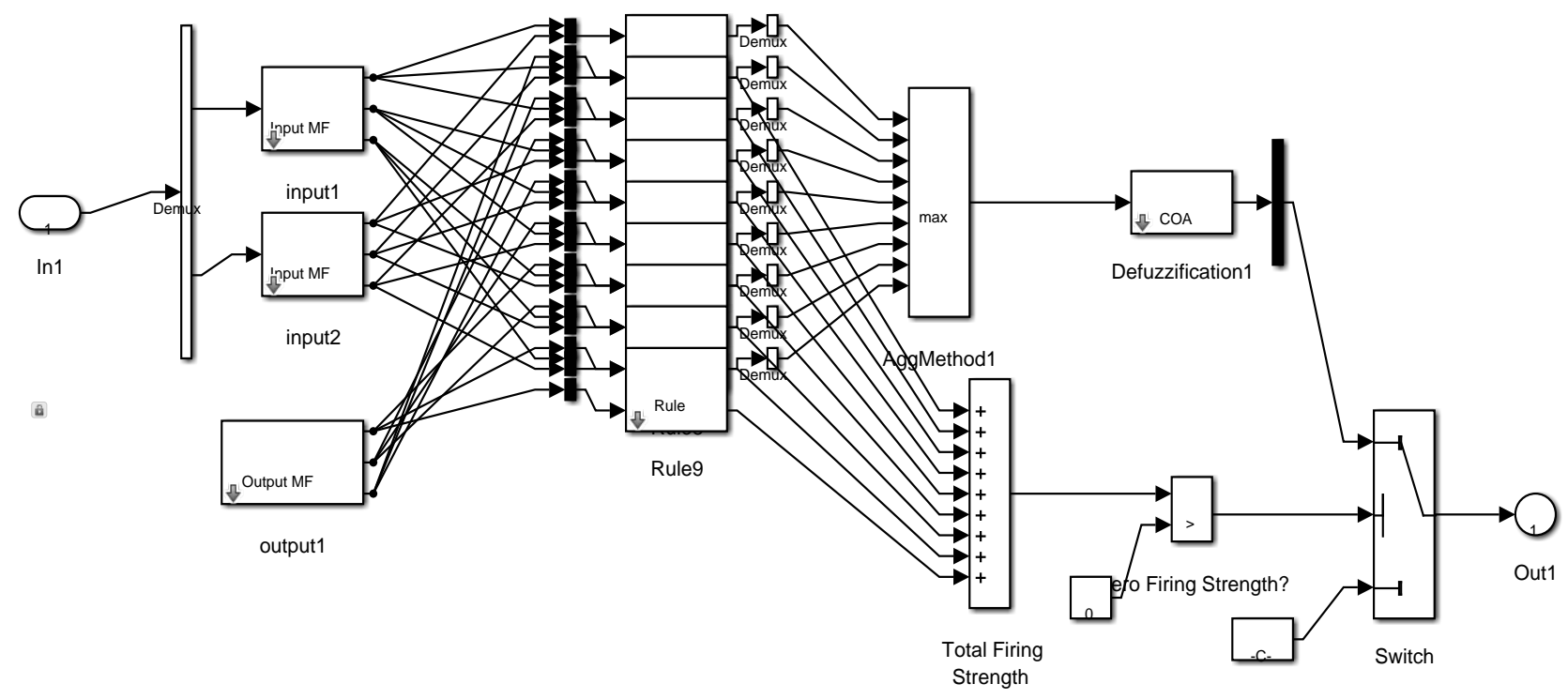

Figure 10. Fuzzy controller (internal structure) configuration of the proposed UPQC system.

\section{Simulation and Discussion of Proposed UPQC System}

Figure 11 demonstrate the structure of the proposed UPQC system simulated using MATLAB, Simulink; A three phase $440 \mathrm{~V}, 50 \mathrm{~Hz}$, three wire power system is considered for this work. The main motivation behind an UPQC is to compensate for supply voltage power quality issues, such as sags, swells, unbalance, flicker, harmonics, and for load current power quality issues, such as harmonics, unbalance reactive current, and neutral current. Two inverters, one related athwart the load which acts as a shunt APF and further related in series with the line as that of series APF. The Shunt coupling inductor $L_{s h}$ is utilized to interface the shunt inverter to the system. It also helps in smoothing the current wave shape. Sometimes an isolation transformer is used to electrically isolate the inverter from the system. A typical dc link can be framed by using a capacitor or an inductor. In Figure 11, the dc link is realized using a capacitor which interrelates the two inverters and similarly keeps a continuous self-supporting dc bus voltage across it. A filter that serves as a passive low-pass filter (LPF) and serves to eliminate high-frequency switching ripples on generated inverter output voltage. Series injection transformer utilized to interface the series inverter in the system. A suitable turn ratio is often considered to decrease the current or voltage rating of the series inverter. In principle, UPQC is an integration of shunt and series APFs with a typical self-supporting dc bus. The shunt inverter in UPQC is controlled in a current control mode such that it offers a current which is equivalent to the set value of the reference current as signified by the UPQC control algorithm. Also, the shunt inverter plays a main part in attaining required performance from an UPQC system by maintaining the dc bus voltage at a set reference value to eliminate the harmonics generated by a nonlinear load.

This circuit is operated under two operating modes, one is Left shunt associated UPQC, and another is right shunt associated UPQC. During left shunt 


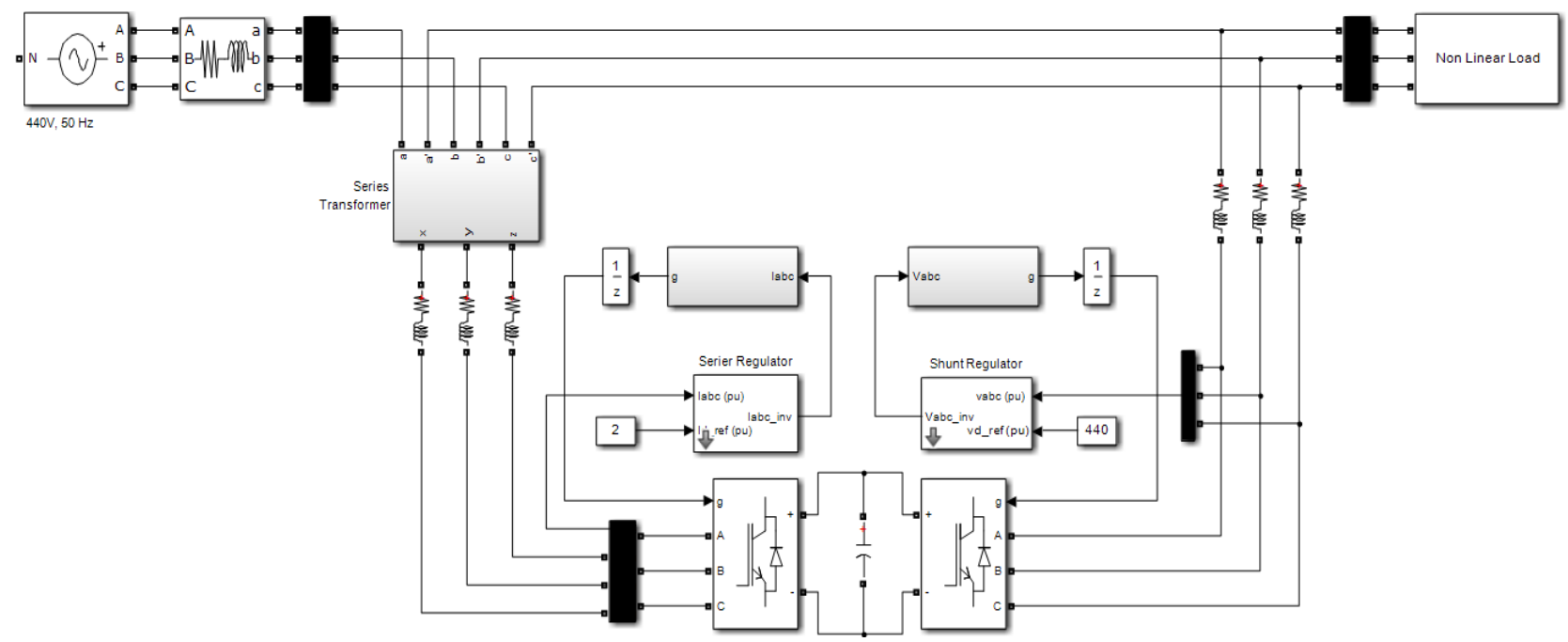

Figure 11. UPQC connected power system configuration with Simulink model structure.

UPQC, the shunt converter is attached to the load side, and the series converter is associated with source side through series injection transformer. Similarly, the right shunt associated system; the converter association is turned around. The proposed UPQC system compensates the load voltage on the source voltage associated with series converter. The control groupings of left and right shunt compensation of UPQC system are done through the series and shunt regulator by providing legitimate gate pulse generation to the UPQC.

\subsection{Left Shunt UPQC System}

Figure 12 demonstrates the source voltage generated by left shunt UPQC associated with the power system. From the Figure 12, it is watched that the input voltage to the three phase system with voltage fluctuation during 0.2 to 0.4 secs. Figure 13 demonstrates the load voltage created by the left shunt UPQC system. From the Figure 13, it is watched that the load voltage generated by the power system with UPQC compensation during 0.2 to 0.4 secs. Figure 14 demonstrates the voltage injected from left shunt UPQC to compensate the load voltage and Figure 15 demonstrates the load current waveform of left shunt UPQC. Figure 16 demonstrates the series current injected from left shunt UPQC to compensate the load current during source voltage fluctuation happened at the time of 0.2 to 0.4 secs. Similarly, Figure 17 demonstrates the shunt voltage from left shunt UPQC. Figure 18 demonstrates the source voltage waveform generated by right shunt associated with the UPQC system. From the Figure 18, it is watched that the input voltage to the three phase system with voltage fluctuation during 0.2 to 0.4 secs before compensation with right shunt associated UPQC. Figure 19 demonstrates the source current waveform of right shunt UPQC before the compensation. Figure 20 demonstrates the load voltage waveform of right shunt UPQC. From the Figure 20, obviously the load voltage of the proposed power system is compensated with right shunt UPQC during 0.2 to 0.4 secs. Similarly, 


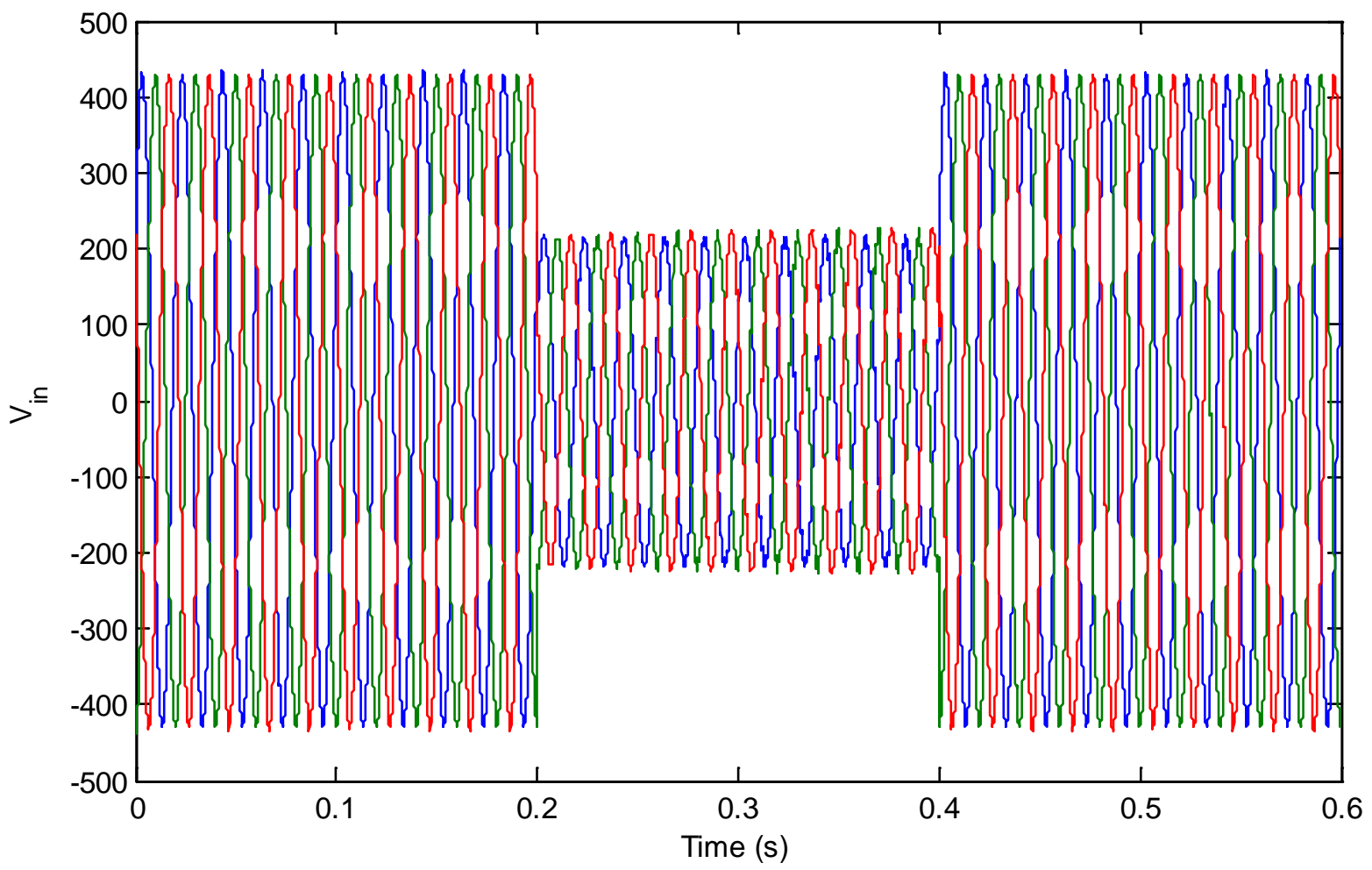

Figure 12. Voltage waveform of proposed power system before compensation with simulated source voltage.

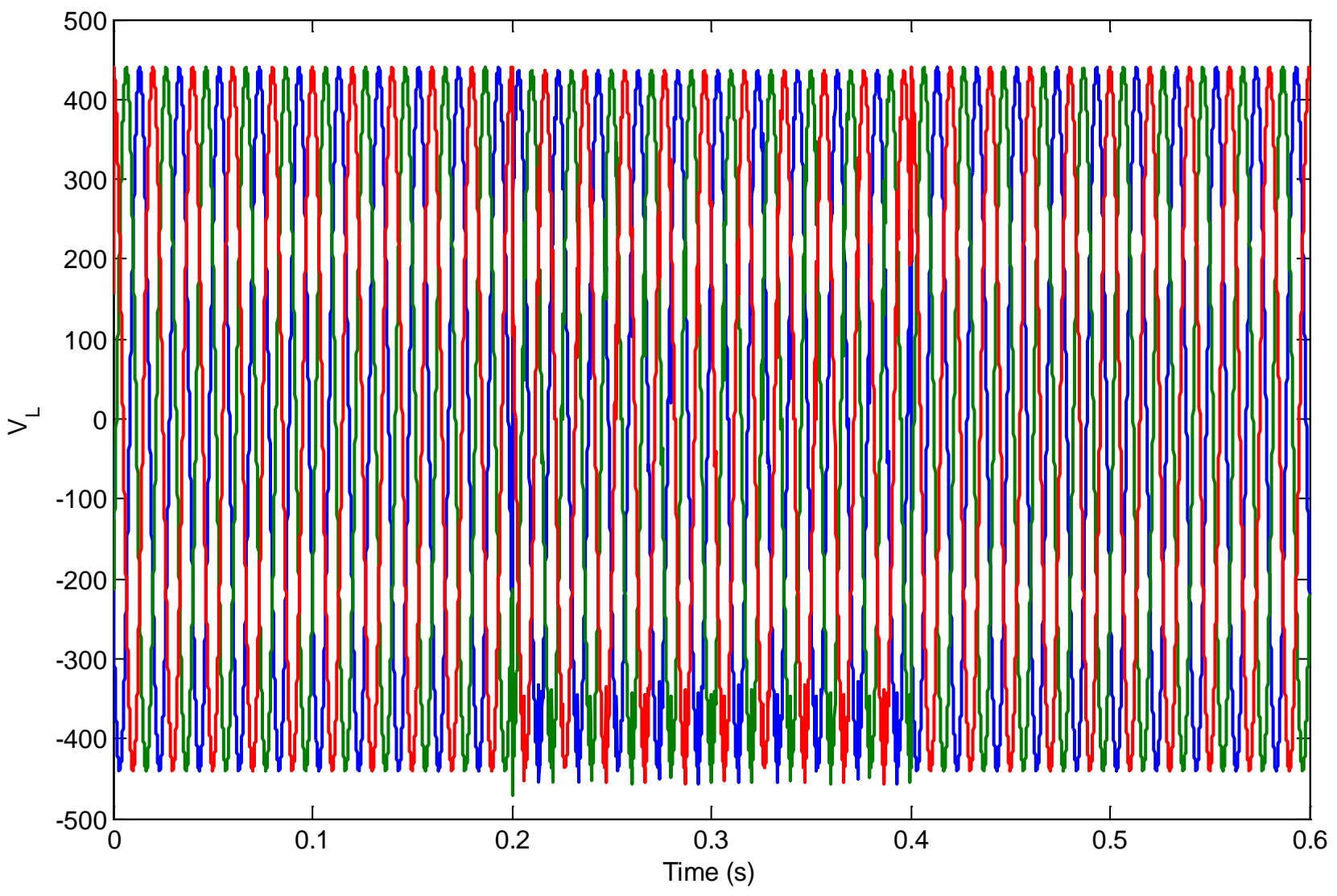

Figure 13. Load voltage waveform simulated output after compensated by left shunt UPQC. 


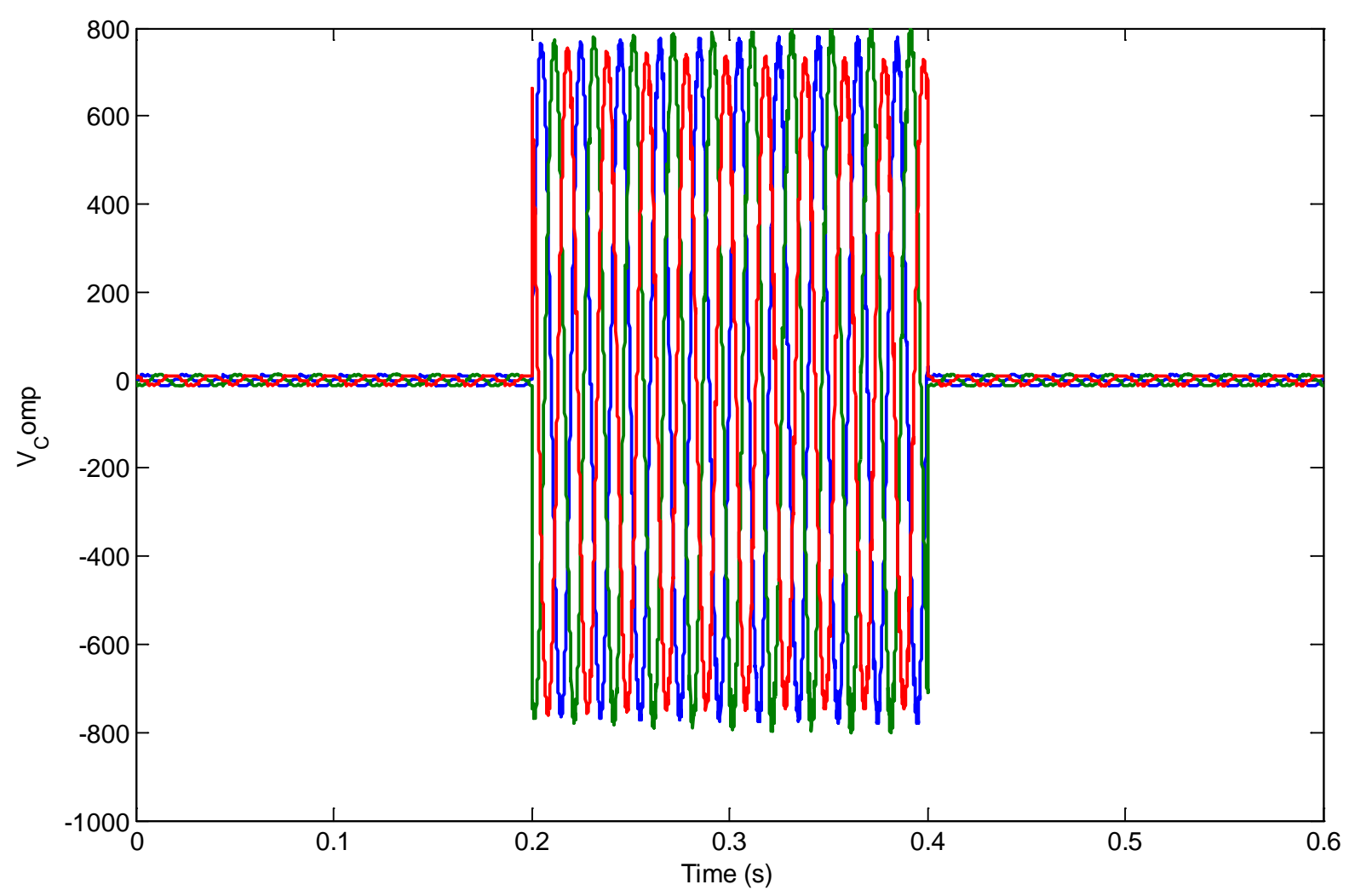

Figure 14. The simulated output of compensation voltage waveform injected by left shunt UPQC.



Figure 15. Output of the load current waveform after compensated by left shunt UPQC. 


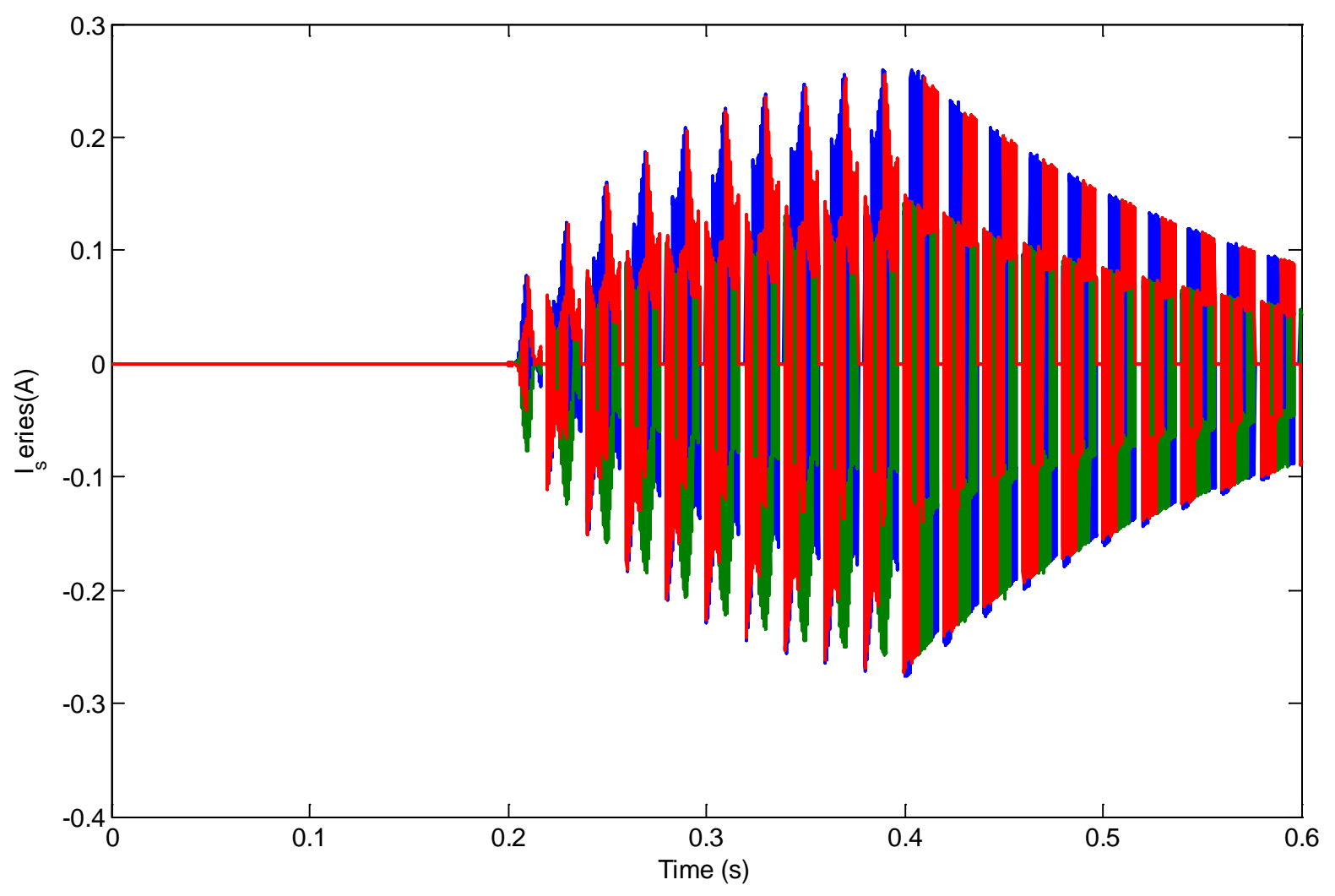

Figure 16. Series current injected waveform from left shunt UPQC.

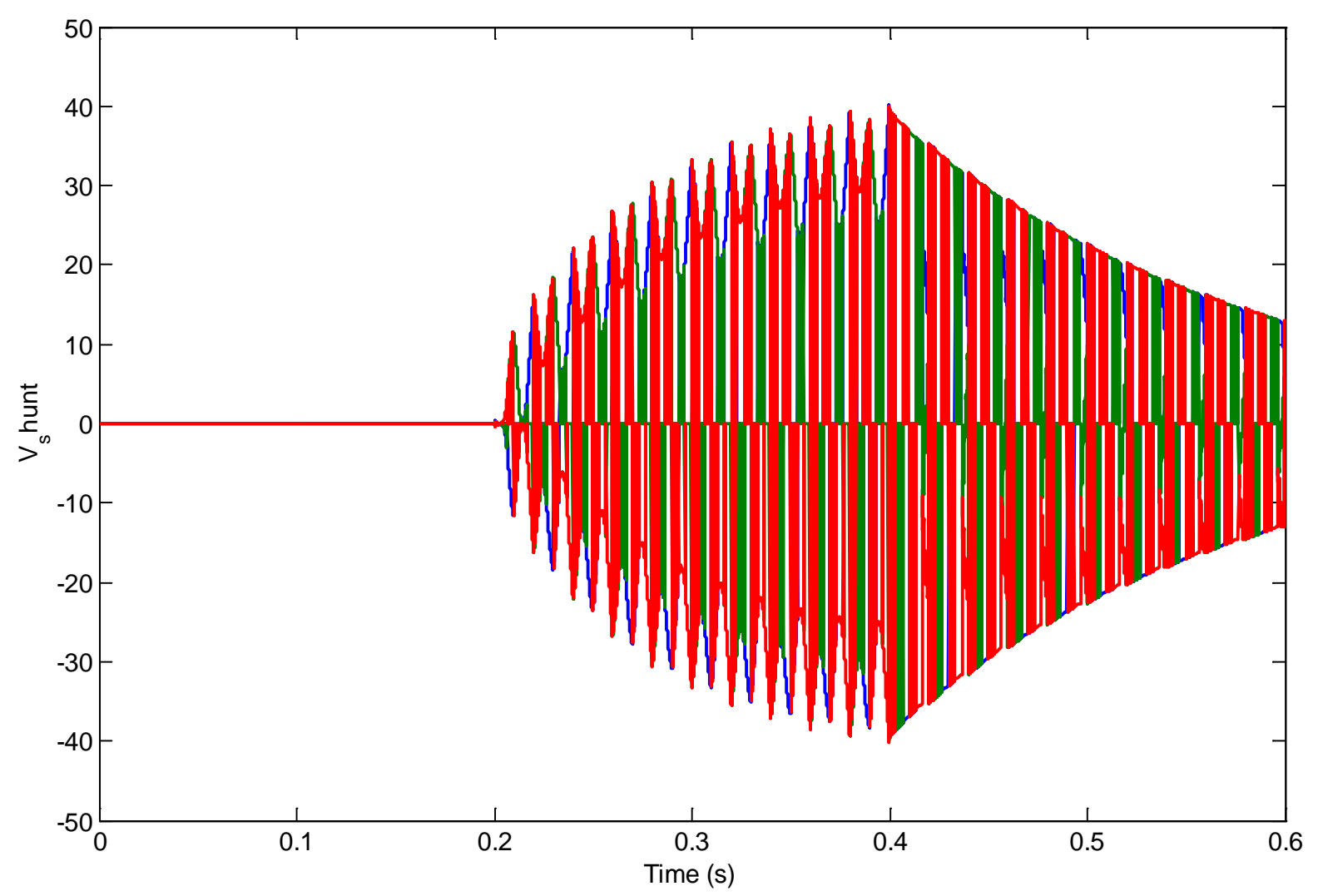

Figure 17. Generated shunt voltage waveform from left shunt UPQC. 


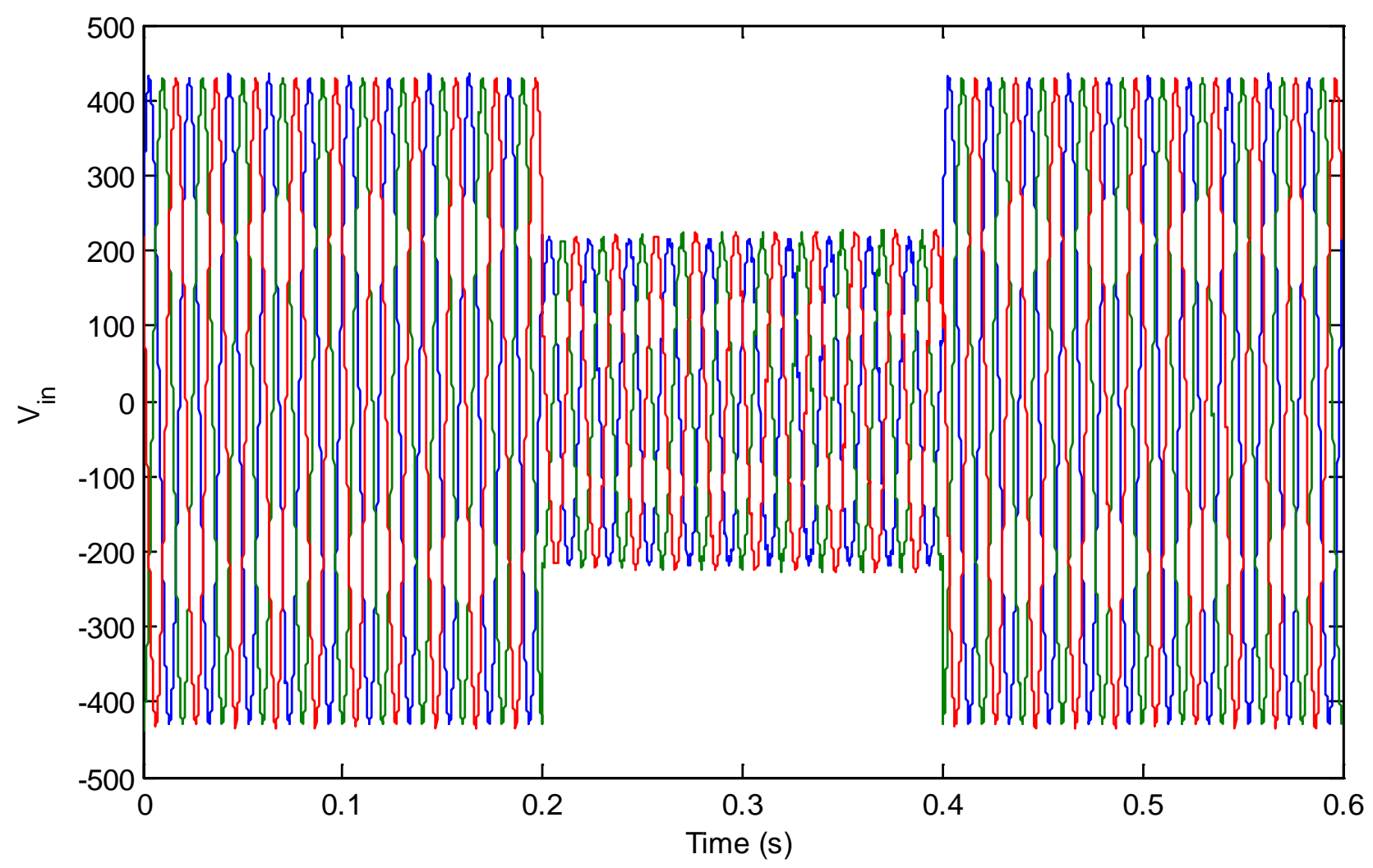

Figure 18. Source voltage waveforms of right shunt UPQC before compensation.

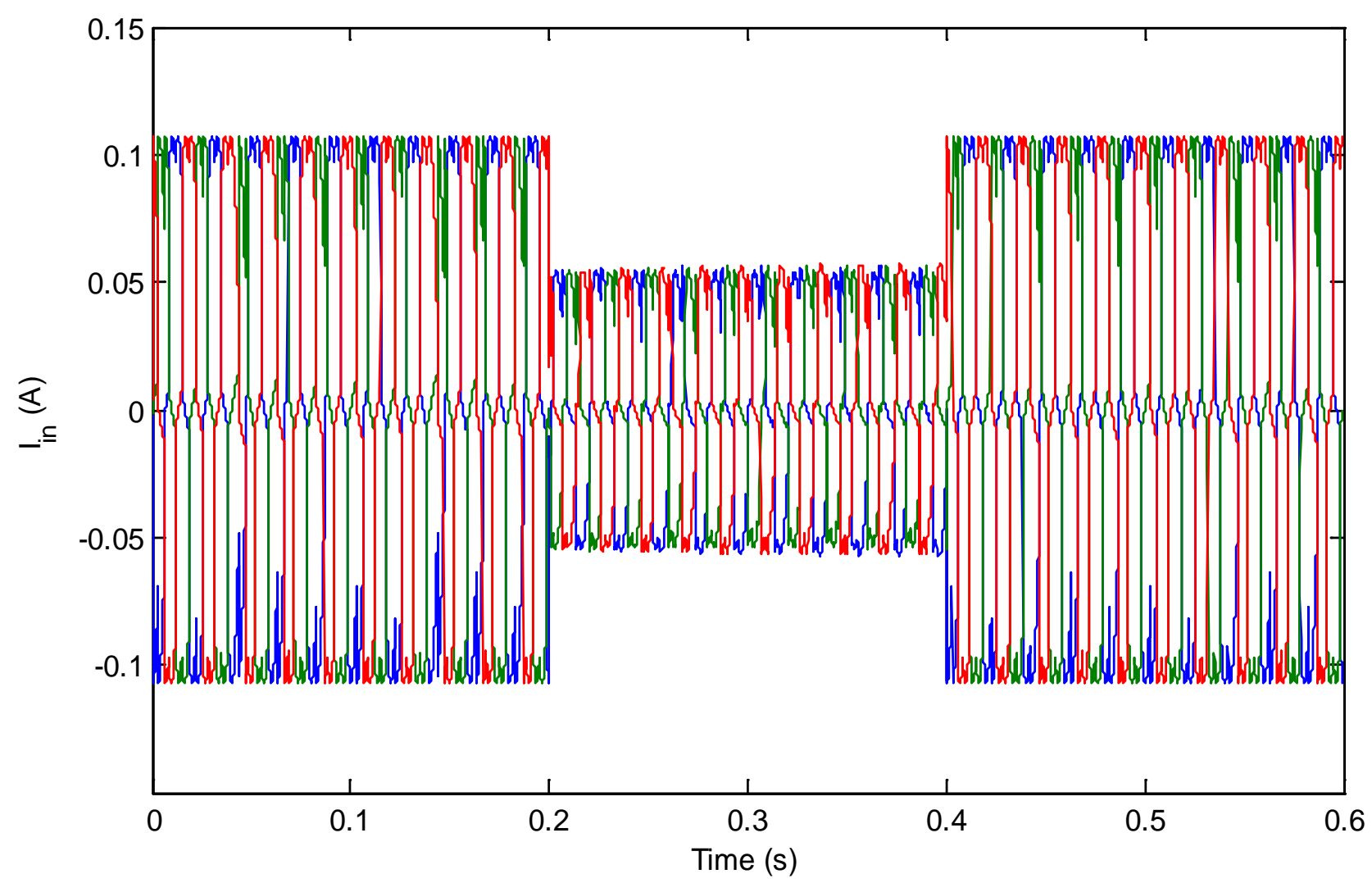

Figure 19. Source current waveforms of right shunt UPQC before compensation. 


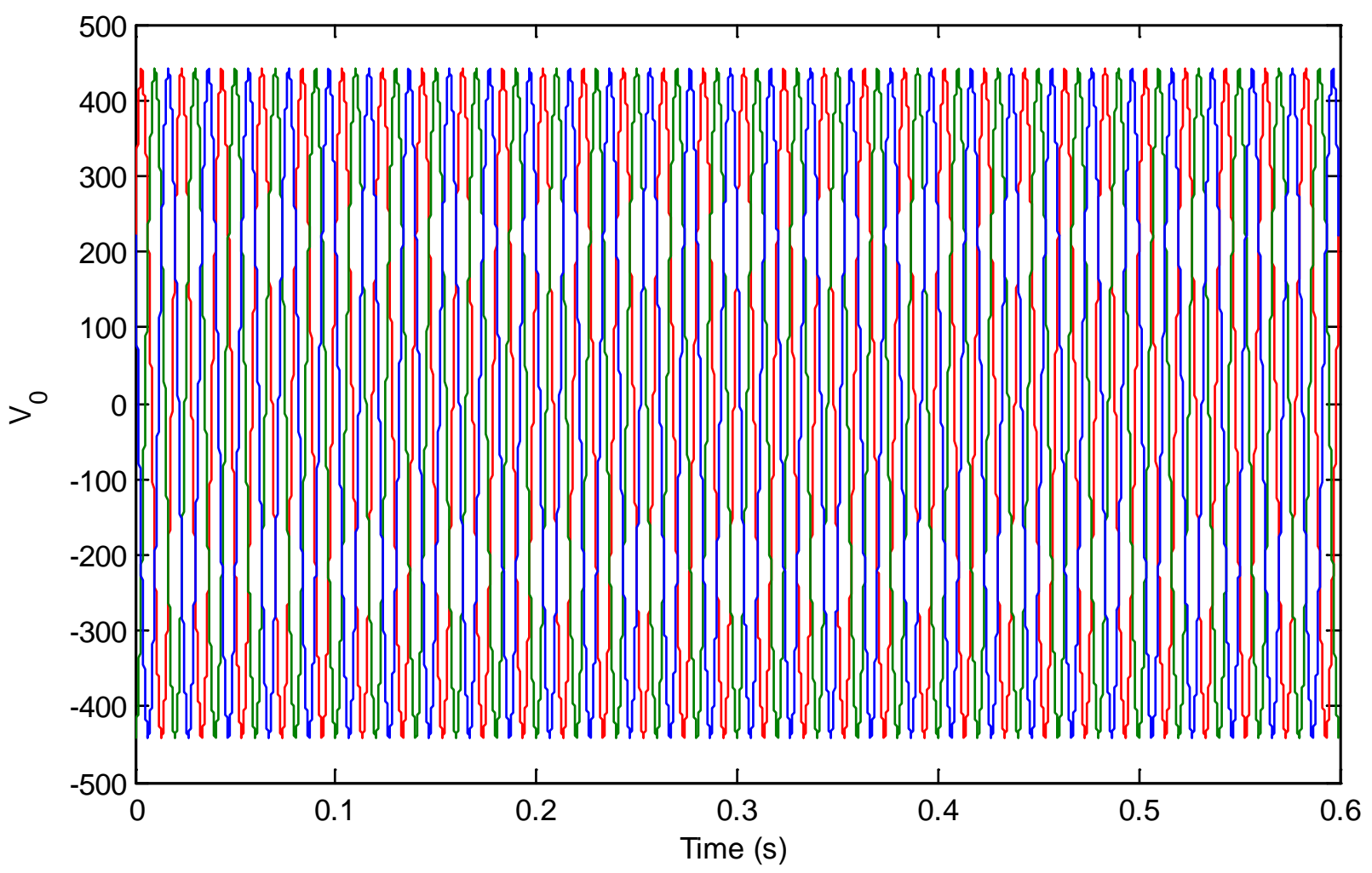

Figure 20. Load voltage waveform after compensation of right shunt UPQC.

Figure 21 demonstrates the load current waveform of right shunt UPQC with right shunt UPQC compensation. Figure 22 demonstrates the compensation voltage waveform injected from right shunt UPQC to compensate the load voltage of the power system. Figure 23 speaks to the series current, Shunt voltage and DC link reaction of right shunt UPQC.

\subsection{Right Shunt UPQC System}

Figure 24 demonstrated the uncompensated and compensated (left shunt and Right shunt) reaction of source current waveform and Figure 25 demonstrated the uncompensated and compensated (left shunt and Right shunt) reaction of the load current waveform. From Figure 24, Figure 25, obviously the waveforms are exceptionally smooth with the nearness of UPQC. The UPQC has compensated the harmonic segment present in the system. Also, obviously the right shunt UPQC waveform is exceptionally smooth compared with left shunt UPQC performance. UPQC compensation voltage and current reactions are exhibited in Figure 26, Figure 27. Figure 26 demonstrates the shunt segment injected voltage reaction of UPQC and Figure 27 demonstrates the series component injected current reactions of the system. Figures 28-30 demonstrated the real and reactive power reactions of uncompensated and compensated (left shunt and right shunt) using UPQC system. Reactive power observation from Figure 29, Figure 30 indicates that lagging compensation in left shunt configuration and leading compensation in right shunt configuration of the UPQC 


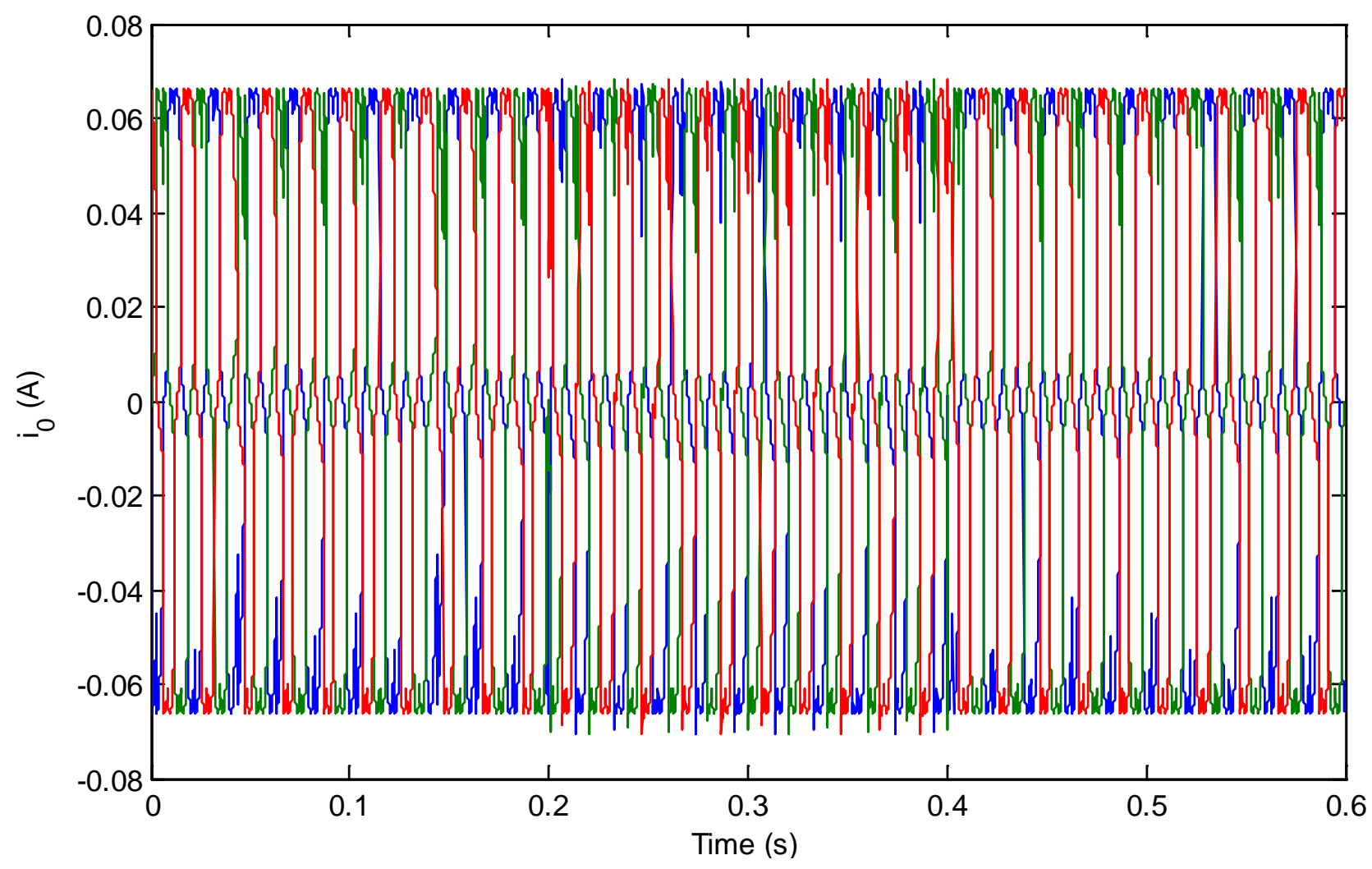

Figure 21. Load current waveform of right shunt UPQC connected power system.

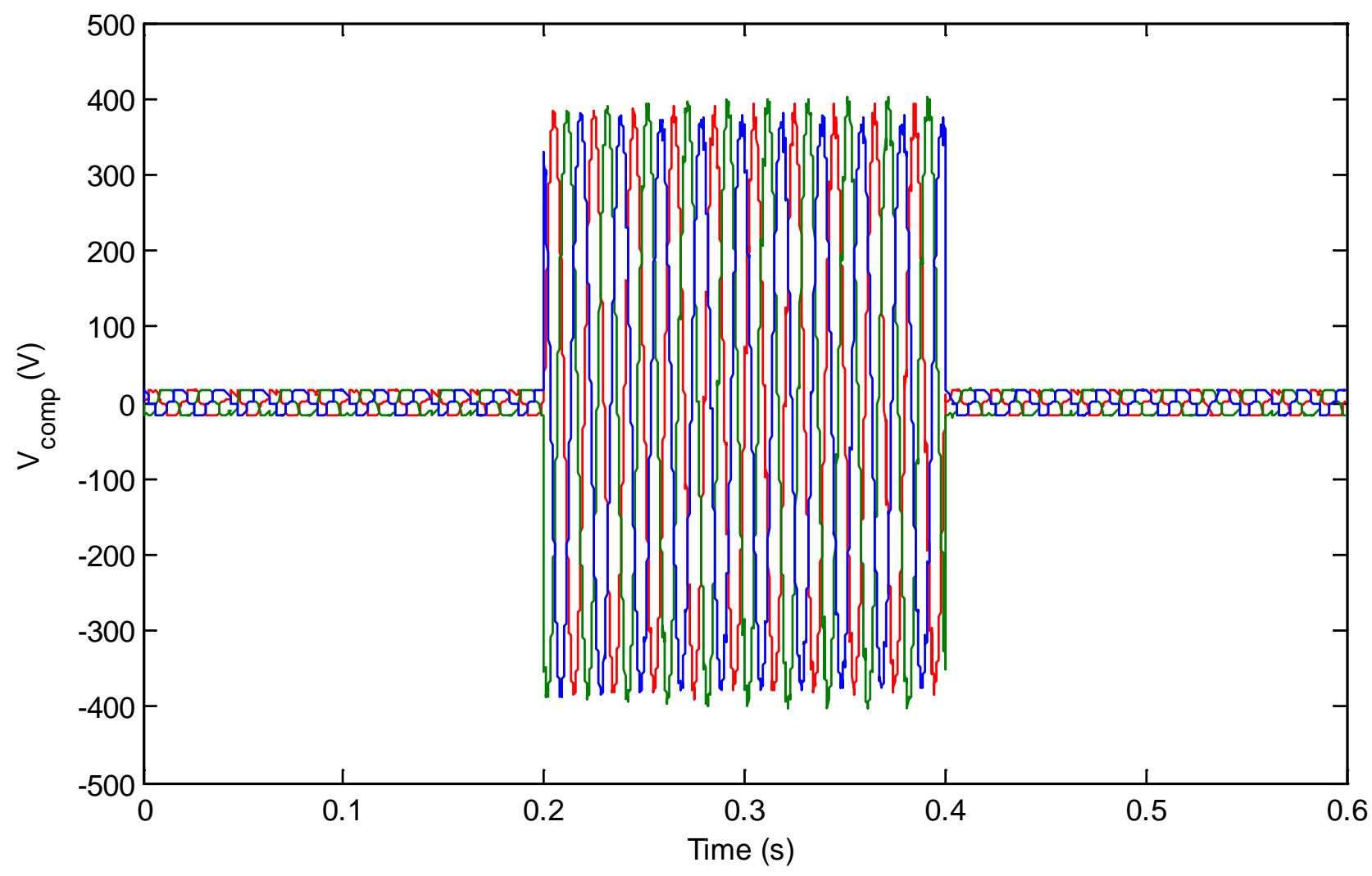

Figure 22. Compensation voltage waveform injected from right shunt UPQC. 

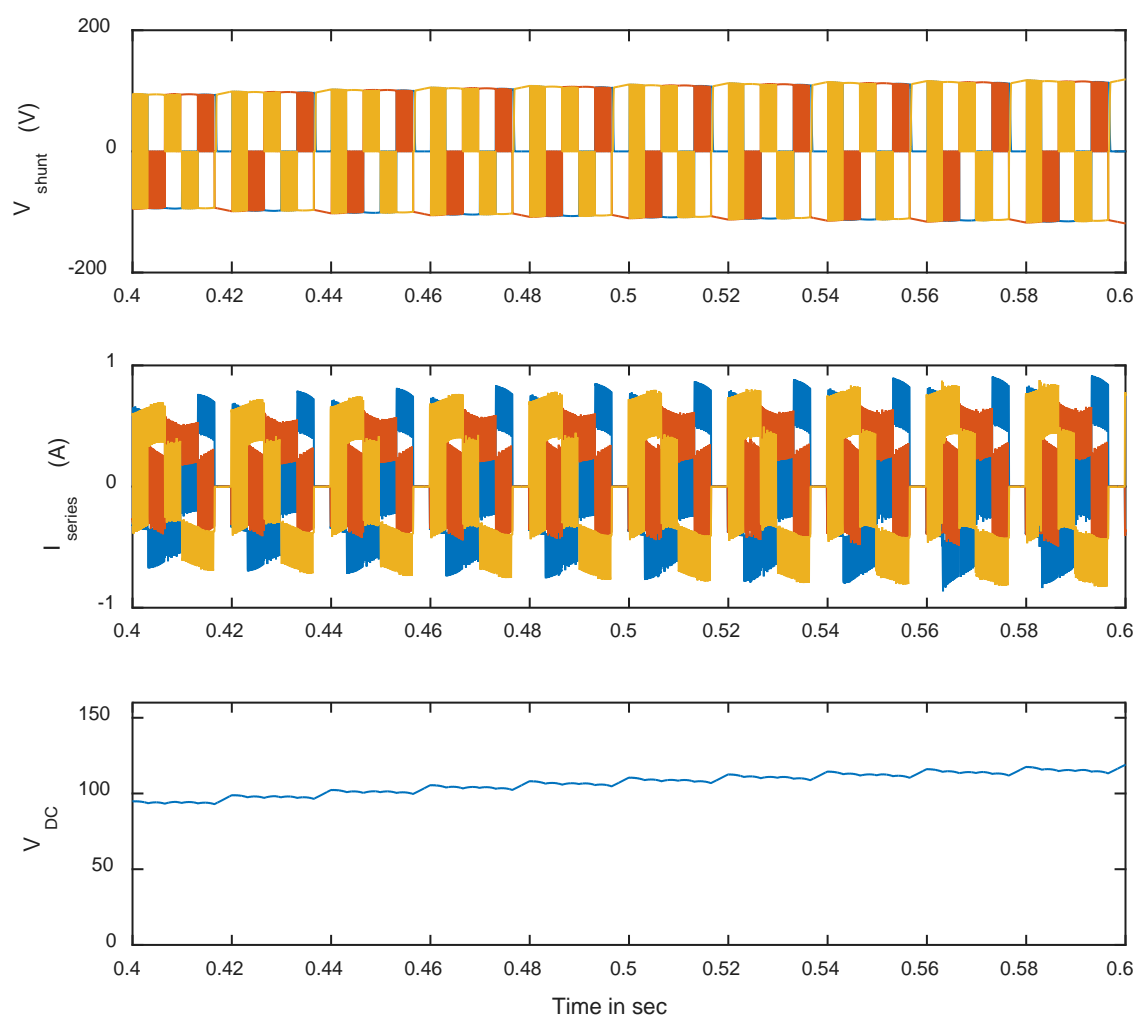

Figure 23. Series current, Shunt voltage and DC link response of right shunt UPQC.
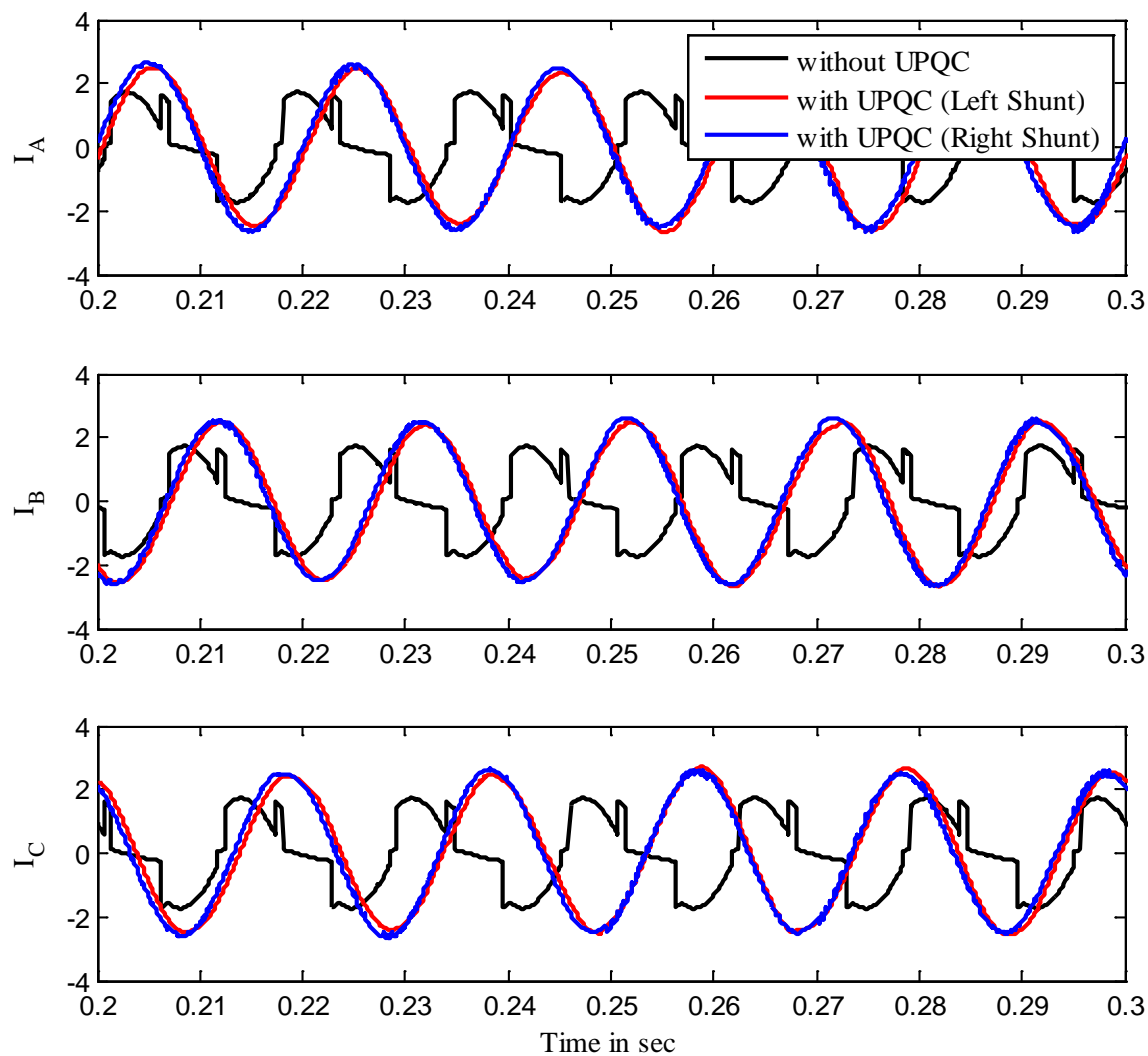

Figure 24. Source side current response of the system without and with UPQC system. 

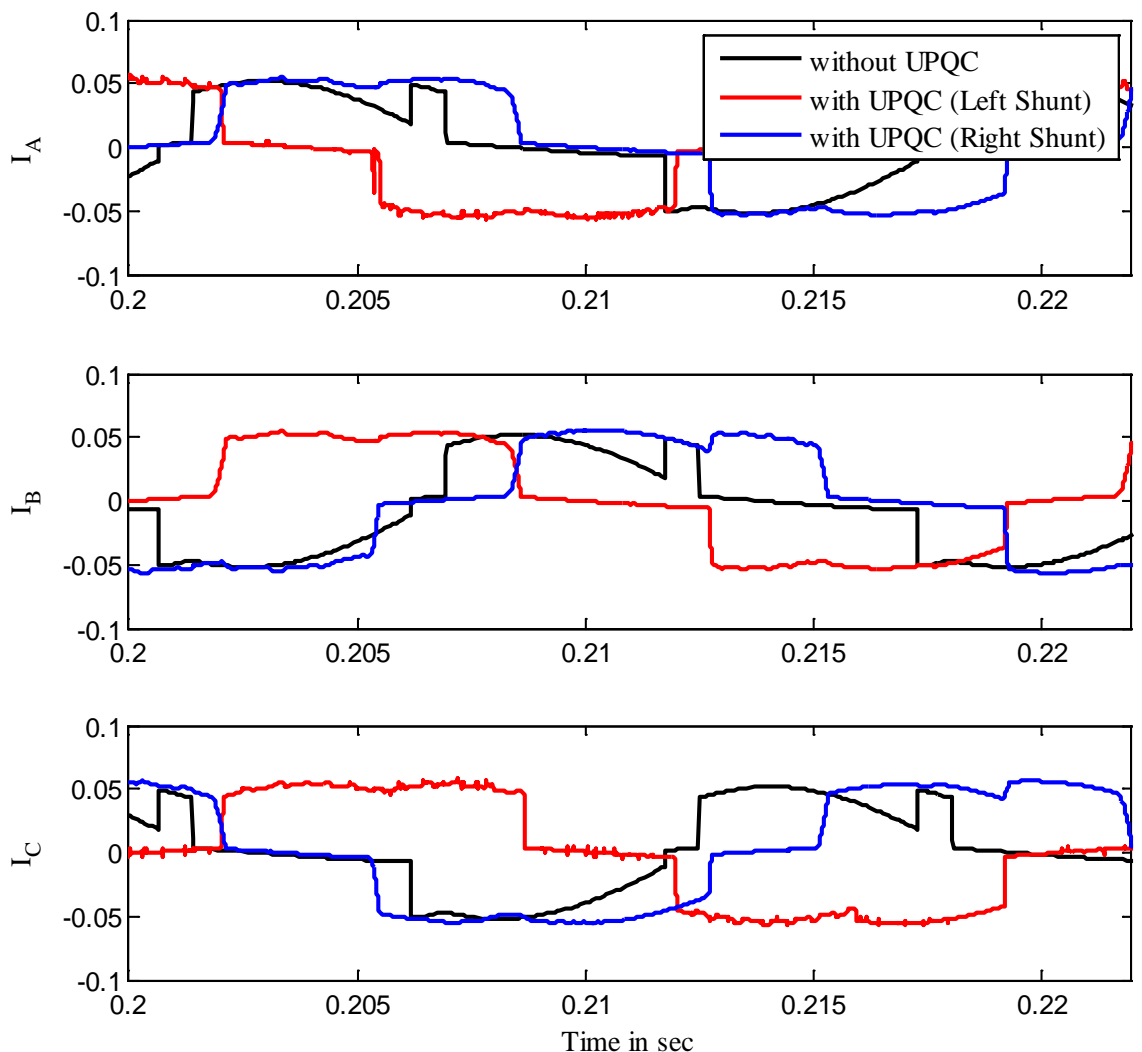

Figure 25. Load side current response of the system without and with UPQC system.
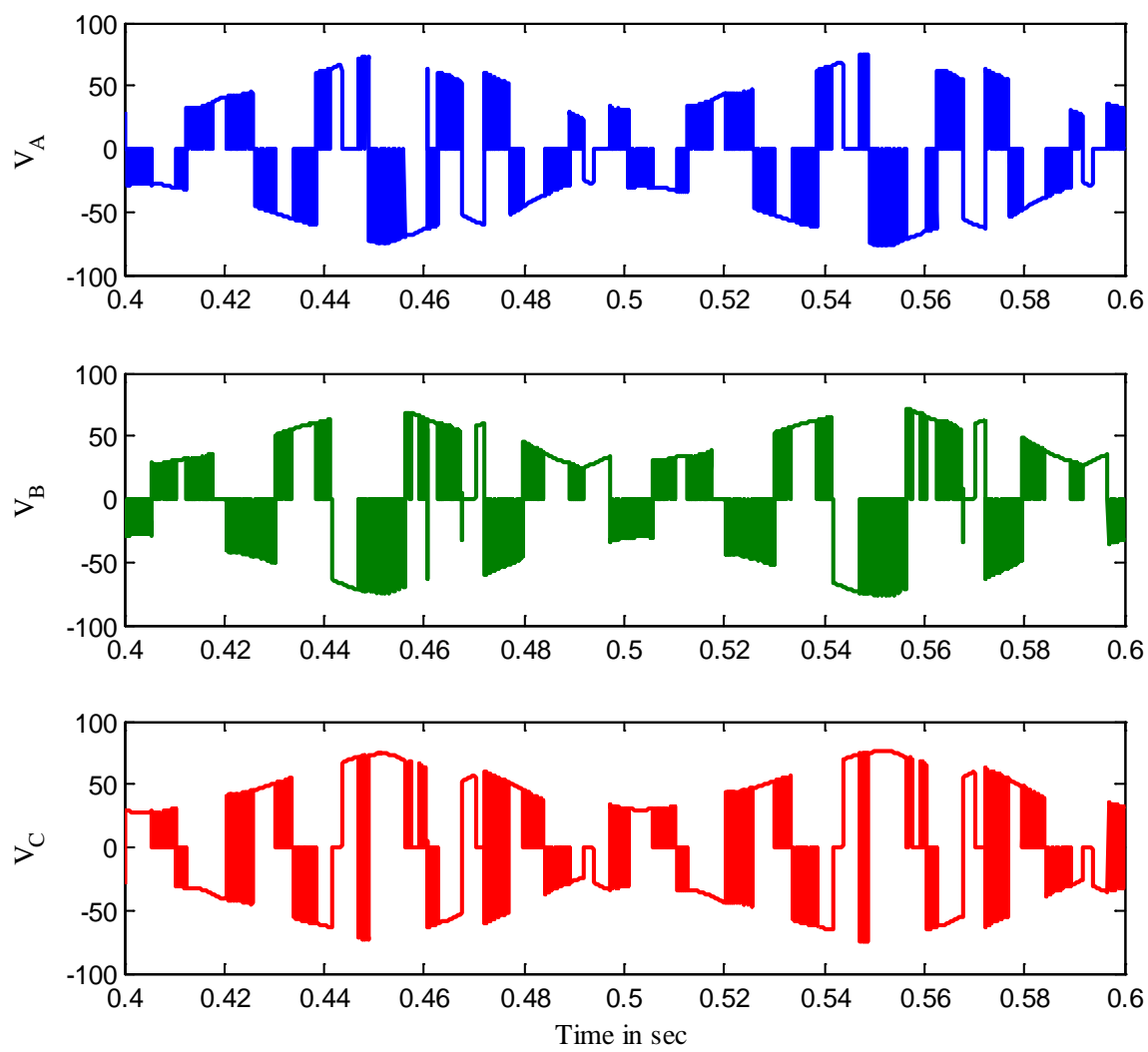

Figure 26. Injected voltage response of Shun connected UPQC. 

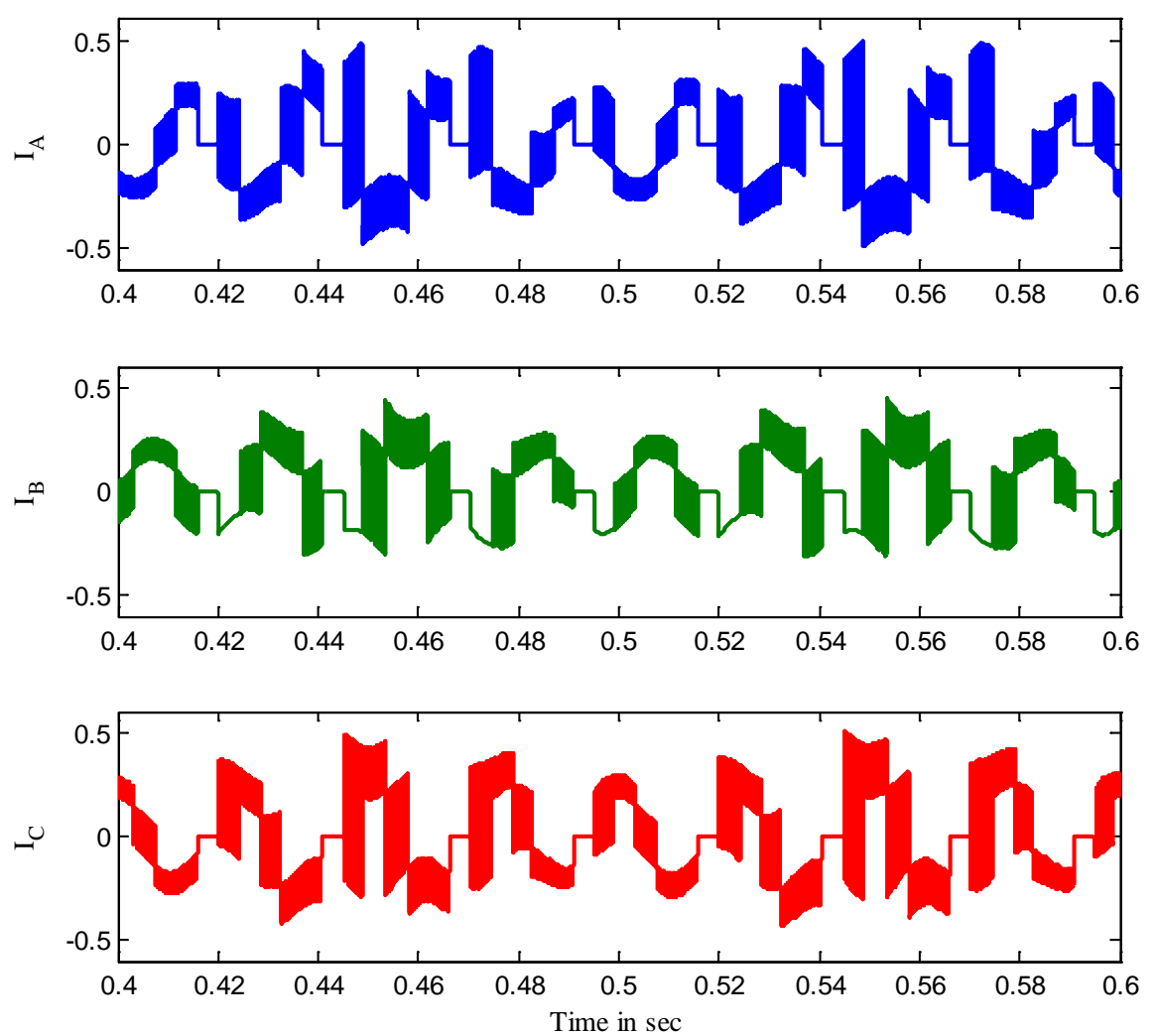

Figure 27. Injected current response of series converter.
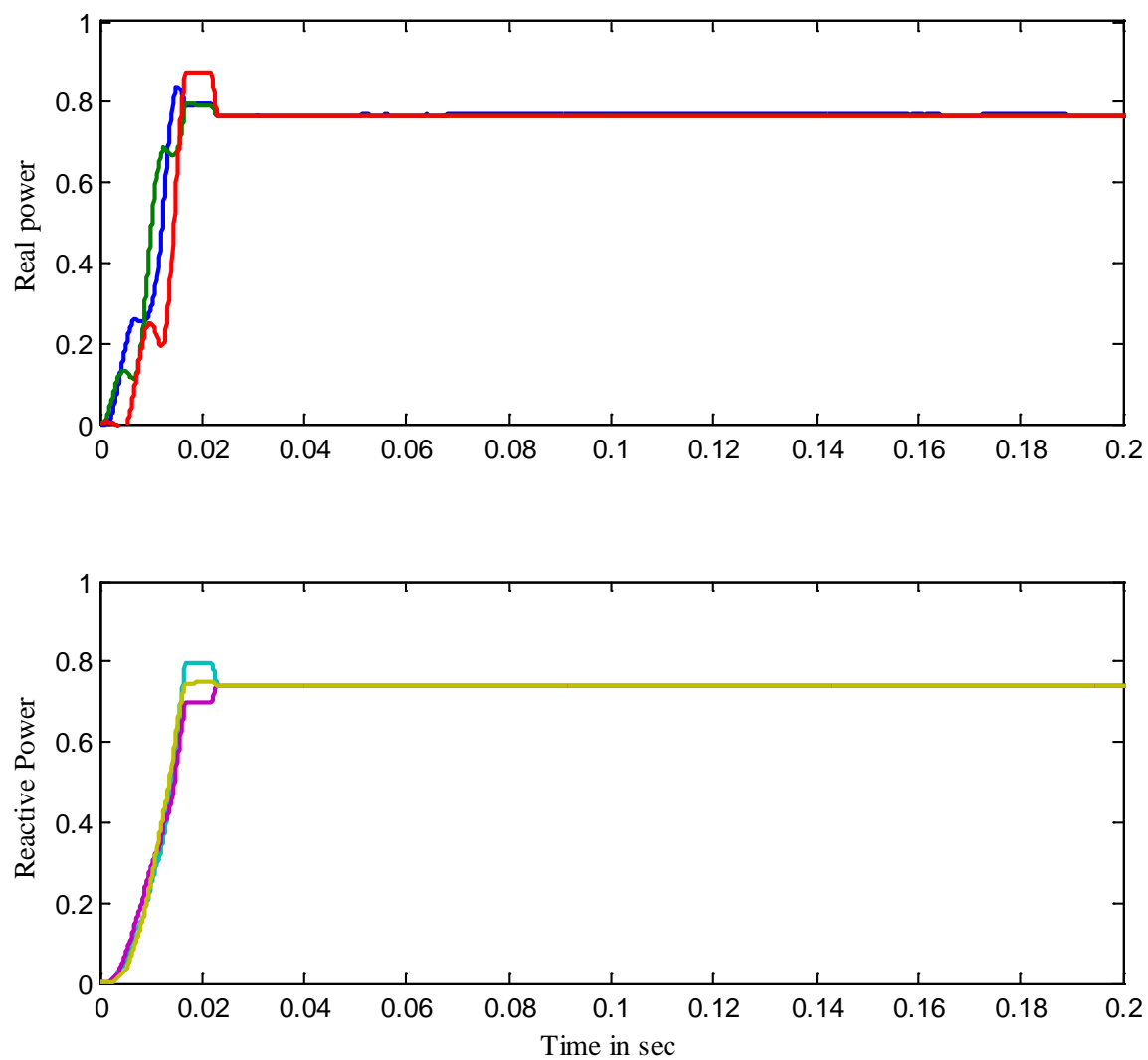

Figure 28. Real and reactive power response for without UPQC. 

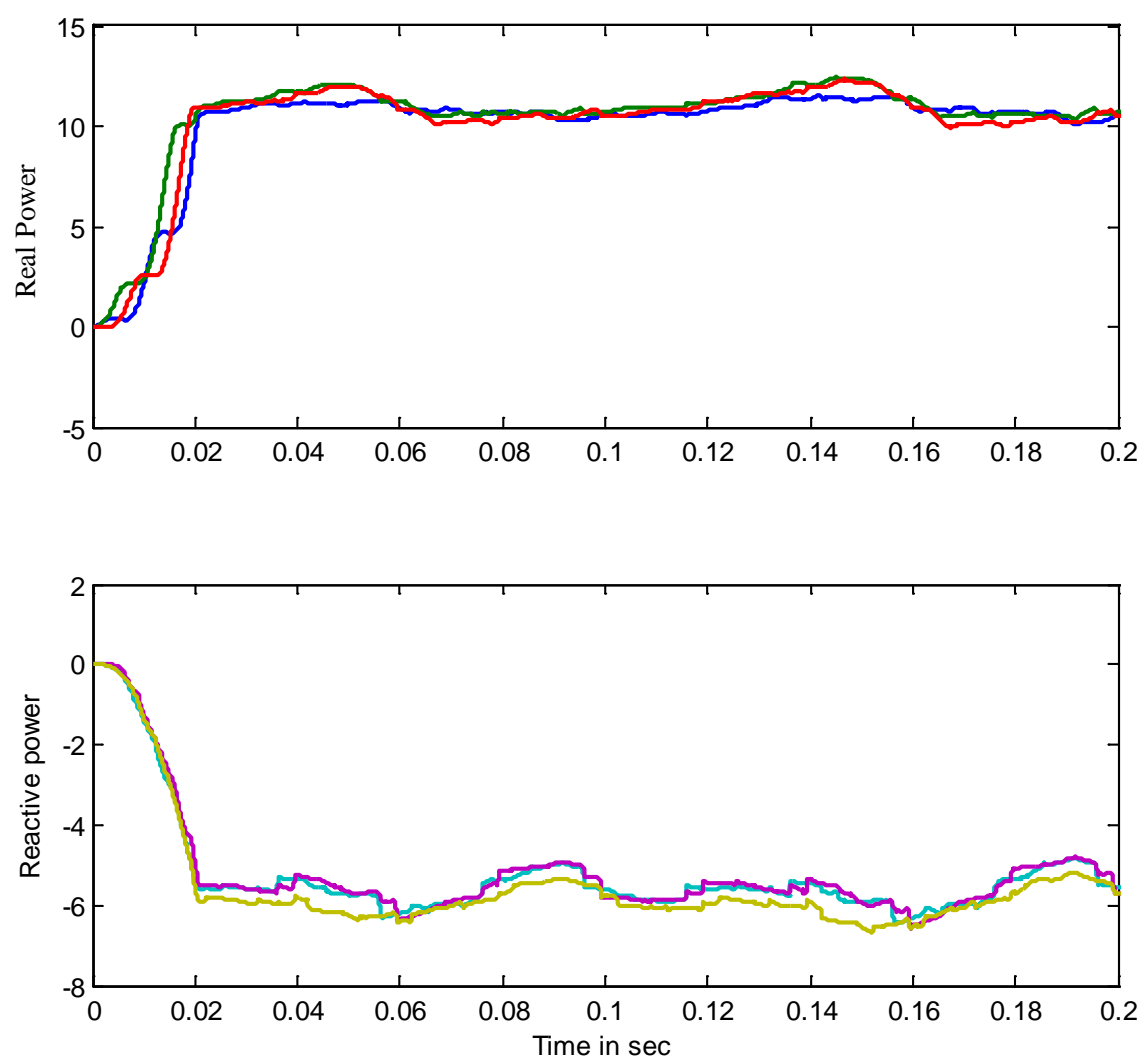

Figure 29. Real and reactive power responses for with right shunt UPQC.
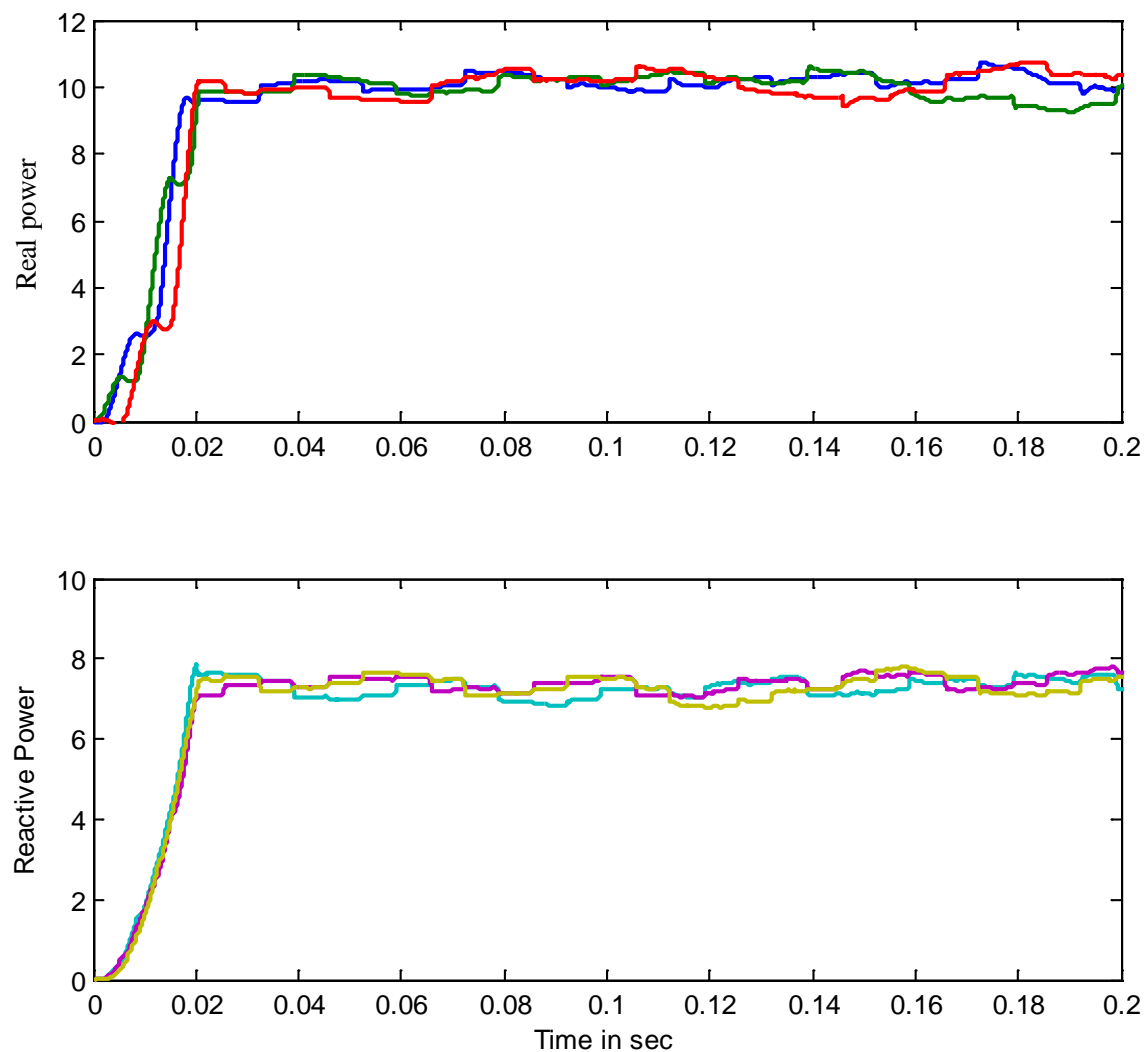

Figure 30. Real and reactive power response for with left shunt UPQC. 


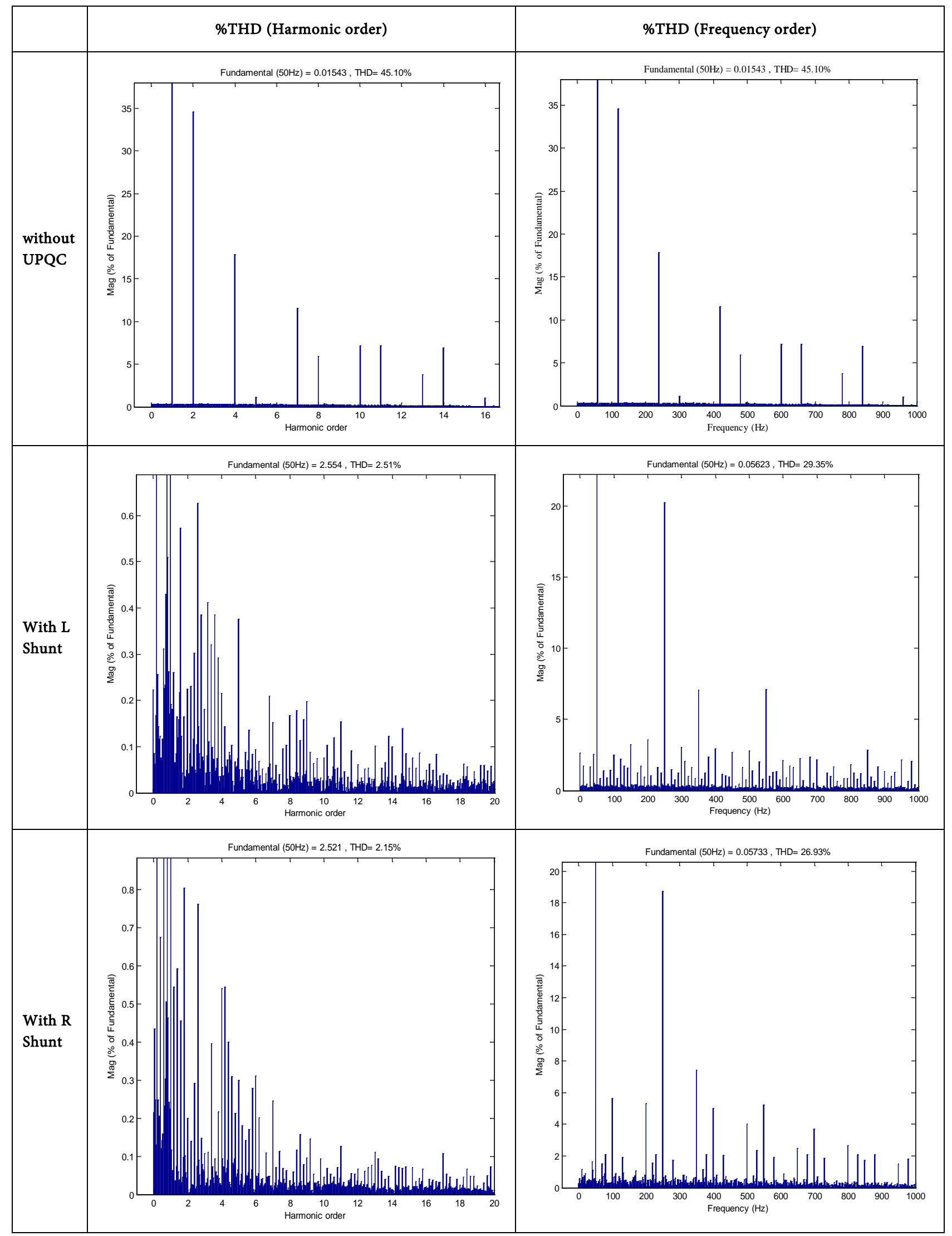

Figure 31. Harmonic analysis of without and with left shunt and right shunt UPQC system. 
Table 1. \% THD analysis of UPQC system.

\begin{tabular}{ccc}
\hline System & \%THD (Harmonic order) & \%THD (Frequency order) \\
\hline Without UPQC & 45.10 & 45.10 \\
Left Shunt UPQC & 2.51 & 29.35 \\
Right Shunt UPQC & 2.15 & 26.93 \\
\hline
\end{tabular}

system. Both left shunt and right shunt evacuate the harmonic part introduce into the system.

Harmonic analysis reaction for uncompensated and compensated (left shunt and right shunt) are introduced in Figure 31. From the Figure 31, unmistakably both left shunt and right shunt associated UPQC system has filtered out a large portion of the harmonic segment found in the system still, right shunt is by all accounts better than left shunt, in which shunt component is nearer to the load side instead of source side in left shunt configuration system. Table 1 indicates \% THD overall harmonic analysis of left and right shunt UPQC system. Table 1 speaks to the overall harmonic analysis of both the left shunt and right shunt associated UPQC system and compared with the conventional system without UPQC. From the comparative performance analysis, the table represents to the right shunt UPQC ends up being better over reactive power compensation.

\section{Conclusion}

A broad simulation study has been displayed in the paper to demonstrate the presence of the left shunt and right UPQC. The load voltage and current are compensated by the implementation of UPQC in left shunt and right shunt of the power system. Also, the reactive power compensation with the magnificent transient reaction is necessary. From the system point of perspective, the performance of the right shunt UPQC and left shunt UPQC applications don't differ all the more, however the right shunt UPQC is performed superior to anything left shunt. In any case, if $100 \%$ terminal voltage compensation has to be given from the UPQC under a voltage sag condition, the right shunt configuration of the UPQC is found to be more economical. In this way, the fuzzy control strategy can lessen the rating of the installed UPQC significantly without compromising on the wanted performance objectives as identified by the network codes. With the implementation of the fuzzy controller, both left, and right shunt UPQC configurations are performed well to expel the harmonics and real and reactive power compensation. Nonetheless, from the overall performance, it is observed that the right shunt UPQC is performed better than left shunt UPQC configuration as appeared in the outcome Table 1.

\section{References}

[1] Aredes, M., Heumann, K. and Watanabe, E.H. (1998) An Universal Active Power Line Conditioner. IEEE Transactions on Power Delivery, 13, 545-551. 
https://doi.org/10.1109/61.660927

[2] Khadkikar, V. and Chandra, A. (2008) A New Control Philosophy for a Unified Power Quality Conditioner (UPQC) to Coordinate Load-Reactive Power Demand between Shunt and Series Inverters. IEEE Transactions on Power Delivery, 23, 2522-2534. https://doi.org/10.1109/TPWRD.2008.921146

[3] Mekri, F., Machmoum, M.A., Mazari, N.A. and Iren, B. (2008) A Fuzzy Hysteresis Voltage and Current Control of a Unified Power Quality Conditioner. 34th Annual Conference of the IEEE Industrial Electronics Society, 44, 2684-2689. https://doi.org/10.1109/IECON.2008.4758382

[4] Muoz, J.A., Espinoza, J.R., Rubilar, L.A., Moran, L.A. and Melin, P.E. (2008) A Modular Approach for Integrating Harmonic Cancellation in a Multi-Cell Based UPQC. 34th Annual Conference of the IEEE Industrial Electronics Society, 21, 3178-3183. https://doi.org/10.1109/IECON.2008.4758469

[5] Jacobina, C.B., Santos, W.R.N., Oliveira, A.C., Da Silva, E.R.C. and Dos Santos, E.C. (2007) Single Phase Universal Active Filter without Transformer. IEEE Applied Power Electronics Conference, 36, 698-703. https://doi.org/10.1109/APEX.2007.357591

[6] Hingorani, N.G. (1995) Introducing Custom Power. IEEE Spectrum, 32, 41-48. https://doi.org/10.1109/6.387140

[7] Takeda, M., Yamamoto, H., Aritsuka, T., Kamiyama, I. and Reed, G.F. (1999) Development of a Novel Hybrid Switch Device and Application to a Solid-State Transfer Switch. Proceedings of the IEEE PES Winter Power Meeting, 2, 1151-1156.

[8] Takeda, M., Murakami, S., Izuka, M., Kishida, Y., Hase, S. and Mochinaga, M. (1995) Development of SVG Series for Voltage Control over Three-Phase Unbalance Caused by Railway Load. International Conference on Power Electronics (IPEC), 1, 603-609.

[9] Reed, G.F., Takeda, M., Iyoda, I., Murakami, S. and Aritsuka, T.K. (1999) Improved Power Quality Solutions Using Advanced Solid-State Switching and Static Compensation Technologies. Proceedings of the IEEE PES Winter Power Meeting, 1, 1132-1137.

[10] Reason, J. (1996) Solid-State Transfer Switch. Electrical World, 1, 56-59.

[11] Schwartzenberg, J.W. and De Doncker, R.W. (1995) $15 \mathrm{kV}$ Medium Voltage Static Transfer Switch. IEEE Industry Application Conference, 3, 2515-1137. https://doi.org/10.1109/IAS.1995.530623

[12] Woodley, N.J., Morgan, L. and Sundaram, A. (1999) Experience with an InverterBased Dynamic Voltage Restorer. IEEE PES Transactions, 14, 1181-1186. https://doi.org/10.1109/61.772390

[13] Mueller, D. (2012) Guide for Application of Power Electronics for Power Quality Improvement on Distribution Systems Rated $1 \mathrm{kV}$ through $38 \mathrm{kV}$. IEEE P1409 Distribution Custom Power Task Force, 1, 1409-2012.

[14] Fujita, H. and Akagi, H. (1998) The Unified Power Quality Conditioner: The Integration of Series and Shunt Active Filters. IEEE Transaction on Power Electronics, 13, 315-322. https://doi.org/10.1109/63.662847

[15] Shayanfar, H.A. and Mokhtarpour, A. (2010) Management, Control and Automation of Power Quality Improvement. In: Eberhard, Ed., Power Quality Book, InTech, Croatia, 127-152.

[16] Hannan, M.A. and Mohamed, A. (2005) PSCAD/EMTDC Simulation of Unified Series-Shunt Compensator for Power Quality Improvement. IEEE Transaction on 
Power Delivery, 20, 1650-1656. https://doi.org/10.1109/TPWRD.2004.833875

[17] Sudharshan, R.G. and Vijay, K.K. (2013) Unified Power Quality Conditioner (UPQC) during Voltage Sag and Swell. International Journal of Emerging Trends in Electrical and Electronics, 1, 12-23.

[18] Jang, J. and Gulley. (1997) MATLAB: Fuzzy Logic Toolbox User's Guide. The Math-Works, Inc., Natick, 19-127.

[19] Jamshidi, M. (1997) Large-Scale Systems: Modeling, Control and Fuzzy Logic. Prentice Hall Series on Environmental and Intelligent Manufacturing Systems, 8, 126134.

[20] Kandel, A. (1992) Fuzzy Expert Systems. CRC Press, Boca Raton, 17-19.

[21] Sugeno, M. and Kang, G.T. (1988) Structure Identification of Fuzzy Model. Journal of Fuzzy Sets and Systems, 28, 15-33. https://doi.org/10.1016/0165-0114(88)90113-3

[22] Kosko, B. (1992) Neural Networks and Fuzzy Systems: A Dynamical Systems Approach to Machine Intelligence. Prentice-Hall International, Upper Saddle River, 23-27.

Submit or recommend next manuscript to SCIRP and we will provide best service for you:

Accepting pre-submission inquiries through Email, Facebook, LinkedIn, Twitter, etc. A wide selection of journals (inclusive of 9 subjects, more than 200 journals) Providing 24-hour high-quality service User-friendly online submission system Fair and swift peer-review system Efficient typesetting and proofreading procedure Display of the result of downloads and visits, as well as the number of cited articles Maximum dissemination of your research work

Submit your manuscript at: http://papersubmission.scirp.org/

Or contact cs@scirp.org 